\title{
Chemical and spectroscopic characterization of marine dissolved organic matter isolated using coupled reverse osmosis-electrodialysis
}

\author{
J.-F. Koprivnjak ${ }^{\mathrm{a}, 1}$, P.H. Pfromm ${ }^{\mathrm{b}}$, E. Ingall ${ }^{\mathrm{a}}$, T.A. Vetter ${ }^{\mathrm{b}, 2}$, P. Schmitt-Kopplin ${ }^{\mathrm{c}}$, \\ N. Hertkorn ${ }^{\text {c }}$, M. Frommberger ${ }^{\text {c }}$, H. Knicker ${ }^{\text {d }}$, E.M. Perdue ${ }^{\mathrm{a}, *}$ \\ ${ }^{a}$ School of Earth and Atmospheric Sciences, Georgia Institute of Technology, 311 Ferst Drive, Atlanta, GA 30332-0340, USA \\ ${ }^{\mathrm{b}}$ Department of Chemical Engineering, Kansas State University, 1005 Durland Hall, Manhattan, KS 66506-5102, USA \\ ${ }^{\mathrm{c}}$ Institute of Ecological Chemistry, Helmholtz Zentrum München, German Research Center for Environmental Health, \\ Ingolstädter Landstraße 1, P.O. Box 1129, D-85758 Neuherberg, Germany \\ ${ }^{\mathrm{d}}$ IRNAS CSIC, Sevilla, Av. Reina Mercedes, 10, 41012 Sevilla, Spain
}

Received 28 July 2008; accepted in revised form 14 April 2009; available online 24 April 2009

\begin{abstract}
The coupled reverse osmosis-electrodialysis (RO/ED) method was used to isolate dissolved organic matter (DOM) from 16 seawater samples. The average yield of organic carbon was $75 \pm 12 \%$, which is consistently greater than the yields of organic carbon that have been commonly achieved using XAD resins, $\mathrm{C}_{18}$ adsorbents, and cross-flow ultrafiltration. UV-visible absorbance spectra and molar $\mathrm{C} / \mathrm{N}$ ratios of isolated samples were consistent with the corresponding properties of DOM in the original seawater samples, indicating that DOM samples can be isolated using the coupled RO/ED method without any bias for/against these two properties. Five of the samples were desalted sufficiently that reliable measurements of their ${ }^{13} \mathrm{C}$ and ${ }^{1} \mathrm{H}$ NMR spectra and their Fourier transform ion cyclotron resonance (FTICR) mass spectra could be obtained. The ${ }^{13} \mathrm{C}$ and ${ }^{1} \mathrm{H}$ NMR spectra of RO/ED samples differed distinctly from those of samples that have been isolated in much lower yields by other methods. In particular, RO/ED samples contained a relatively lower proportion of carbohydrate carbon and a relatively greater proportion of alkyl carbon than samples that have been isolated using cross-flow ultrafiltration. From the FTICR mass spectra of RO/ED samples, samples from the open ocean contained a much lower proportion of unsaturated compounds and a much higher proportion of fatty acids than coastal samples.
\end{abstract}

(C) 2009 Elsevier Ltd. All rights reserved.

\section{INTRODUCTION}

Dissolved organic carbon (DOC) in the oceans is one of the largest dynamic reservoirs of carbon on earth, comparable in size to the atmospheric reservoir of carbon (as $\left.\mathrm{CO}_{2}\right)$ in the atmosphere, or to the amount of carbon in all terrestrial and aquatic biota (Hedges et al., 1997). The concerted

\footnotetext{
${ }^{*}$ Corresponding author. Fax: +1 4048945638.

E-mail address: mperdue@eas.gatech.edu (E.M. Perdue).

${ }^{1}$ Present address: Trent University, Ont., Canada.

${ }^{2}$ Present address: Koch Industries, Wichita, KS, USA.
}

efforts of earth scientists, atmospheric scientists, and biologists who study global biogeochemical cycles and the earth's climate have yielded a rather detailed understanding of carbon in the atmosphere and in biota. Marine dissolved organic matter (DOM) is far less well characterized, principally because it exists as a highly diluted mixture of perhaps millions of organic compounds in a highly saline aqueous solution.

This paper builds upon many prior efforts to isolate DOM from seawater using XAD resins, $\mathrm{C}_{18}$ adsorbents, and cross-flow ultrafiltration, sharing with those studies the goal of obtaining relatively large quantities of representative, low-ash samples that can be studied to learn much 
more about the origin, reactions, and fate of DOM in seawater. Some seminal references to that body of literature are the studies of Stuermer and Harvey (1974), Mills and Quinn (1981), Benner et al. (1992, 1997), Druffel et al. (1992), Koch et al. (2005), and the recent comprehensive review by Mopper et al. (2007). The immense challenge in such research is brought into perspective by noting that seawater typically contains around $35,000 \mathrm{mg} \mathrm{L}^{-1}$ of dissolved sea salts and $0.5-1.0 \mathrm{mg} \mathrm{L}^{-1}$ of DOC, the lower DOC concentrations being found in the deeper ocean (most of the ocean reservoir). The mass ratio of sea salts to DOM in seawater (assuming that $\mathrm{DOM} \approx \mathrm{DOC} \times 2$ ) is therefore 17,500:1 or higher. To obtain representative samples of isolated marine DOM that are suitable for the widest array of methods of chemical and spectroscopic characterization, virtually all of the salts in seawater must be removed, the bulk of the water must be removed, and a large, representative fraction of the DOM must be retained.

When DOM is isolated from fresh waters by XAD-8 resin or by cross-flow ultrafiltration using a $1 \mathrm{kDa}$ membrane, the median yields of DOM from a large number of studies are $56 \%$ and $71 \%$, respectively (Perdue and Ritchie, 2003). When these methods are applied to saline waters, yields vary with salinity but, in non-coastal samples, typical yields are $25 \%$ or less (Mopper et al., 2007; Perdue and Benner, 2009). Reverse osmosis (RO) has been used for nearly 20 years to concentrate DOM from fresh waters (e.g., Serkiz and Perdue, 1990; Clair et al., 1991; Sun et al., 1995; Kitis et al., 2001). The median recovery of DOM from a large number of fresh waters by reverse osmosis is $90 \%$ (Perdue and Ritchie, 2003). The RO method concentrates not only DOM but also $\mathrm{H}_{4} \mathrm{SiO}_{4}$ and $\mathrm{H}_{2} \mathrm{SO}_{4}$. Electrodialysis (ED) was finally found to be the solution to the removal of these inorganic contaminants, when Koprivnjak et al. (2006) demonstrated that both $\mathrm{H}_{4} \mathrm{SiO}_{4}$ and $\mathrm{H}_{2} \mathrm{SO}_{4}$ could be removed from RO-concentrated solutions of DOM using ED, while recovering an average of $85 \%$ of DOM.

Building on the results of Koprivnjak et al. (2006), a coupled RO/ED method has been developed and applied to 16 samples of seawater. Most of the technical details of the coupled RO/ED method and yields of DOM for a subset of the samples have been reported by Vetter et al. (2007) and Gurtler et al. (2008). This paper supplements those data with detailed information regarding sampling locations, removal of water and sea salts, and recovery of DOM for all remaining seawater samples. More importantly, chemical and spectroscopic data that have thus far been obtained for five of the samples are presented, analyzed, and discussed.

\section{EXPERIMENTAL METHODS}

\subsection{Collection of seawater samples}

The shipboard tests were performed aboard the R/V Savannah in July, 2006 and October, 2006 during research cruises in the open Atlantic Ocean off the coast near Savannah, Georgia. The general location of the study area is given in Fig. 1, and details regarding the 16 samples are given in Table 1. Samples S706-1-S706-10 were collected in July, 2006, and samples S1006-1-S1006-6 were collected in October, 2006. Two samples were collected on the Georgia coast near the mouth of the Ogeechee River, three samples were collected in the open Atlantic Ocean, and 11 samples were collected in the Gulf Stream. Only five samples were collected at depths of more than $20 \mathrm{~m}$, including an open ocean sample at $860 \mathrm{~m}$, a Gulf Stream sample at $322 \mathrm{~m}$, and three Gulf Stream samples at 77, 84, and $84 \mathrm{~m}$, where the maximum level of chromophoric DOM (CDOM) was detected during sampling. Detailed procedures for collection of the seawater samples were described by Vetter et al. (2007) and Gurtler et al. (2008).

\subsection{The RO/ED process for isolation of DOM from seawater}

An overview of the coupled RO/ED process for isolation of DOM from seawater was provided by Vetter et al. (2007), and the process was described in detail by Gurtler et al. (2008). In the initial ED phase, the salinity of the sam-

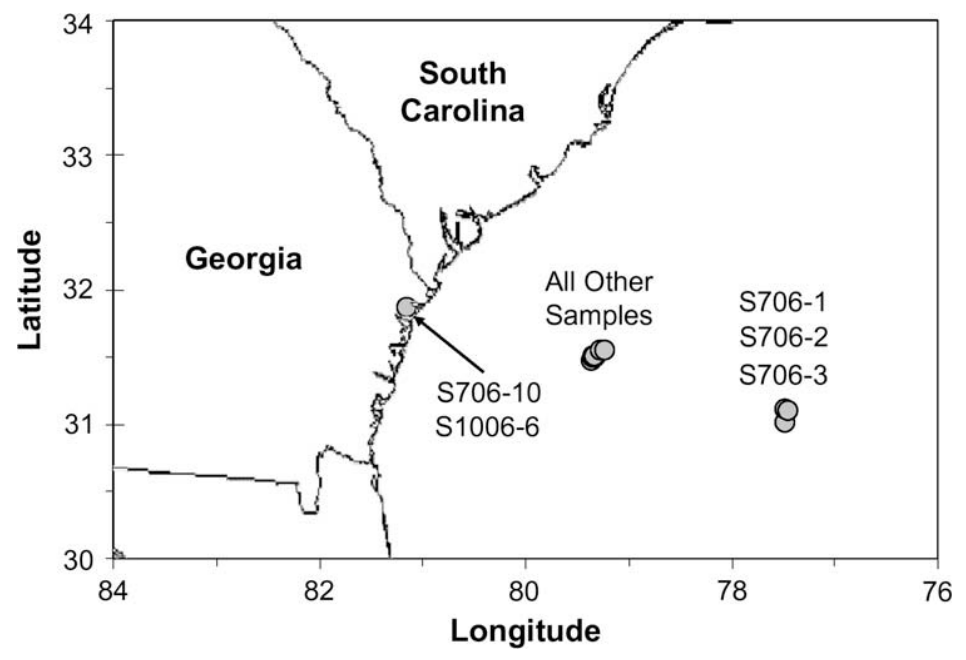

Fig. 1. Location of sampling sites (see Table 1 for details). 
Table 1

Location of sampling sites.

\begin{tabular}{lllcl}
\hline Site & Latitude & Longitude & Depth $(\mathrm{m})$ & Description \\
\hline S706-1 & $31^{\circ} 05.9^{\prime}$ & $77^{\circ} 28.5^{\prime}$ & 20 & Open Atlantic-East of Gulf Stream \\
S706-2 & $31^{\circ} 06.1^{\prime}$ & $77^{\circ} 28.9^{\prime}$ & 860 & Open Atlantic-East of Gulf Stream \\
S706-3 & $31^{\circ} 05.9^{\prime}$ & $77^{\circ} 27.2^{\prime}$ & 20 & Open Atlantic-East of Gulf Stream \\
S706-4 & $31^{\circ} 28.2^{\prime}$ & $79^{\circ} 21.4^{\prime}$ & 20 & Gulf Stream \\
S706-5 & $31^{\circ} 30.3^{\prime}$ & $79^{\circ} 18.7^{\prime}$ & 322 & Gulf Stream \\
S706-6 & $31^{\circ} 29.5^{\prime}$ & $79^{\circ} 19.2^{\prime}$ & 77 & Gulf Stream - CDOM maximum $^{\text {a }}$ \\
S706-7 & $31^{\circ} 30.1^{\prime}$ & $79^{\circ} 19.4^{\prime}$ & 20 & Gulf Stream \\
S706-8 & $31^{\circ} 30.0^{\prime}$ & $79^{\circ} 20.3^{\prime}$ & 20 & Gulf Stream \\
S706-9 & $31^{\circ} 29.4^{\prime}$ & $79^{\circ} 20.2^{\prime}$ & 20 & Gulf Stream \\
S706-10 & $31^{\circ} 51.6^{\prime}$ & $81^{\circ} 09.2^{\prime}$ & 2 & Ogeechee River mouth, high tide \\
S1006-1 & $31^{\circ} 30.3^{\prime}$ & $79^{\circ} 19.4^{\prime}$ & 20 & Gulf Stream \\
S1006-2 & $31^{\circ} 32.8^{\prime}$ & $79^{\circ} 14.3^{\prime}$ & 20 & Gulf Stream \\
S1006-3 & $31^{\circ} 32.6^{\prime}$ & $79^{\circ} 15.7^{\prime}$ & 20 & Gulf Stream \\
S1006-4 & $31^{\circ} 32.5^{\prime}$ & $79^{\circ} 13.8^{\prime}$ & 84 & Gulf Stream - CDOM maximum \\
S1006-5 & $31^{\circ} 32.5^{\prime}$ & $79^{\circ} 13.8^{\prime}$ & 84 & Gulf Stream - CDOM maximum ${ }^{\text {a }}$ \\
S1006-6 & $31^{\circ} 51.6^{\prime}$ & $81^{\circ} 09.1^{\prime}$ & 2 & Ogeechee River mouth, high tide \\
\hline
\end{tabular}

${ }^{a} \mathrm{CDOM}$ is chromophoric dissolved organic matter.

ple was reduced from around 50 to $15 \mathrm{mS} \mathrm{cm}^{-1}$, which caused the osmotic pressure of the sample to decrease from around $2610 \mathrm{kPa}$ (379 psi) to around $786 \mathrm{kPa}$ (114 psi). During the RO/ED phase, water was removed by RO at an operating pressure of $1380-1725 \mathrm{kPa}(200-250 \mathrm{psi})$ until the volume of the sample was reduced to $10 \mathrm{~L}$ or less, and sea salts were removed concomitantly by ED to maintain a constant conductivity of $15 \mathrm{mS} \mathrm{cm}^{-1}$. In the final ED phase, the conductivity of the now-concentrated DOM sample ( $\sim 40 \mathrm{ppm}$ of DOM) was reduced to its final target value $\left(10 \mathrm{mS} \mathrm{cm}^{-1}\right.$ in the July, 2006 cruise and $0.1 \mathrm{mS} \mathrm{cm}^{-1}$ or less in the October, 2006 cruise).

\subsection{Electrodialysis system}

During ED, sea salts were transferred from the diluate (the sample being desalted) to the concentrate (the solution into which the ions are transferred). The ED stack and its operation, both in the laboratory and at sea, were described by Vetter et al. (2007) and Gurtler et al. (2008). During the final ED phase, electric power was provided by a $150 \mathrm{~V}, 8 \mathrm{~A}$ DC power supply (Sorensen DCS series). For some samples, electric power was cycled on/off at two-second intervals during the final ED phase of desalting in an attempt to remove additional sea salts without additional loss of DOC (Gurtler et al., 2008).

\subsection{Reverse osmosis system}

Two RO systems equipped with spiral-wound RO tapwater membranes (FilmTec TW30-4021, The Dow Chemical Company, Midland, MI) were used. One RO system was equipped with a Standex Procon CMP-7500 SS pump (Procon, Murfreesboro, TN) and the other with a stainless steel rotary vane pump powered by a $1 \mathrm{HP}$ electric motor (type $82395 \mathrm{~K} 88$, McMaster-Carr, Cleveland, OH). Either RO system could supply $1200 \mathrm{~L} \mathrm{~h}^{-1}$ of sample to the RO element at a pressure of $1380-1725 \mathrm{kPa}(200-250 \mathrm{psi})$ or be used to produce relatively pure water ( $\mathrm{RO}$ permeate) from the ship's supply of drinking water. This RO permeate was used as reagent water, rinse water, and especially to lower the conductivity of the ED concentrate solution as needed during the ED process.

\subsection{Procedural blank}

The ship's drinking water supply was processed by RO to obtain a sufficient volume of low-conductivity, lowTOC RO permeate solution for use as a procedural blank, which was processed exactly like a sample (filtration, rinsing the RO/ED system, processing, etc.), with one exception. Because the blank contained insufficient solutes to conduct electricity, the ED system was operated without a potential across the membrane stack. The time the sample was circulated through the RO and ED systems was the same as had been used for actual samples.

\subsection{Analytical methods}

Conductivity and $\mathrm{pH}$ were measured at regular intervals during the $\mathrm{RO} / \mathrm{ED}$ process, using a hand-held, temperature-compensated conductivity meter (Oakton 300 Series) and an Orion 720A pH meter. Voltage and current readings were regularly taken directly from the DC power supply. All samples for DOC analysis were collected in $40 \mathrm{~mL}$ glass vials. The samples were refrigerated immediately and analyzed within one week. DOC was measured using a Shimadzu TOC-VCSN high-temperature combustion analyzer (Shimadzu Scientific Instruments, Columbia, MD) using standard protocols for seawater (e.g., Benner and Strom, 1993). The system blank of the Shimadzu analyzer was estimated to be $0.16 \mathrm{mg}$ TOC/L. This was the average difference between TOC measurements for purified laboratory water on the Shimadzu analyzer and a Sievers 800 carbon analyzer (GE Analytical Systems, Boulder, CO). The Sievers carbon analyzer uses a combination of photo- and chemical oxidation to oxidize DOM and has no inherent system blank. 
The yield of DOC in an experiment was calculated as

Yield $(\%)=100\left(\frac{\mathrm{DOC}_{\text {final }}+\mathrm{DOC}_{\text {rinse }}}{\mathrm{DOC}_{\text {initial }}-\mathrm{DOC}_{\text {sacrificed }}}\right)$

where all DOC terms have units of $\mu \mathrm{mol}$. DOC $\mathrm{sacrificed}$ is the quantity of DOC that was sacrificed for sub-sampling during the RO/ED method.

\subsection{UV-visible absorbance spectrometry}

UV-visible absorbance measurements were obtained using a $1-\mathrm{cm}$ quartz cell in a Hewlett-Packard 8451A diode array UV-visible spectrophotometer. Absorption coefficients were calculated as

$a(\lambda)=2.303 A(\lambda) / r$

where $A(\lambda)$ is the absorbance at wavelength $\lambda$, and $r$ is the optical path length in units of meters. Absorption coefficients over a range of $290-350 \mathrm{~nm}$ were fit to the following exponential equation

$a(\lambda)=a\left(\lambda_{0}\right) \mathrm{e}^{-S \lambda}$

where $a\left(\lambda_{0}\right)$ is the absorption coefficient at a reference wavelength $\lambda_{0}$, and $S$ is the spectral slope parameter (Blough and Green, 1995; Kitidis et al., 2006). In addition, the specific UV absorption coefficient at $300 \mathrm{~nm}$ was calculated as

SUVA $_{300}=a(300) /[\mathrm{DOC}]$

where $[\mathrm{DOC}]$ is the concentration of DOC in units of $\mathrm{mg} \mathrm{L}^{-1}$.

\subsection{Molar $\mathrm{C} / \mathrm{N}$ ratios}

Molar $\mathrm{C} / \mathrm{N}$ ratios were calculated from measurements of organic carbon and nitrogen on five samples. An aliquot of each desalted, concentrated liquid sample from the final ED phase of the coupled RO/ED process (one sample, S706-1, was further desalted by ED in the laboratory) was freezedried, and the dry sample was homogenized using an agate mortar and pestle. The percentages of organic $\mathrm{C}$ and organic $\mathrm{N}$ were determined with a Costech elemental analyzer using methods described in Hedges and Stern (1984).

\section{9. ${ }^{13} \mathrm{C}$ NMR spectrometry}

Five samples were analyzed by solid-state ${ }^{13} \mathrm{C}$ NMR spectroscopy using a Bruker DSX 200 NMR spectrometer operating at a resonance frequency of $50.32 \mathrm{MHz}$ and using a zirconium rotor of $7 \mathrm{~mm}$ outer diameter with a KELFcap. A KELF-inlet was put into the rotor to adjust the low sample amount in the coil volume. The cross polarization magic angle spinning (CPMAS) technique (Schaefer and Stejskal, 1976) was applied with a spinning speed of $6.8 \mathrm{kHz}$ and a pulse delay of $1 \mathrm{~s}$. Spectra were obtained after accumulation of 40,000 to 80,000 scans. A ramped ${ }^{1} \mathrm{H}$-pulse was used during the contact time of $1 \mathrm{~ms}$ to circumvent spin modulation during the Hartmann-Hahn contact (Cook et al., 1996; Peersen et al., 1993). Line broadenings between 10 and $100 \mathrm{~Hz}$ were applied. The ${ }^{13} \mathrm{C}$ chemical shifts were calibrated relative to tetramethylsilane $(0 \mathrm{ppm})$.

\subsection{0. ${ }^{1} \mathrm{H}$ NMR spectrometry}

${ }^{1} \mathrm{H}$ NMR spectra were acquired on solutions containing $1-2 \mathrm{mg}$ of DOM in approximately $650 \mathrm{mg}$ of $0.1 \mathrm{M} \mathrm{NaOD}$ (99.95\% ${ }^{2} \mathrm{H}$, Merck, Darmstadt). Spectra were acquired at $303 \mathrm{~K}$ with a $5 \mathrm{~mm}$ z-gradient ${ }^{13} \mathrm{C} /{ }^{1} \mathrm{H}$ dual cryogenic probe using $90^{\circ}$ excitation pulses $\left(90^{\circ}\left({ }^{1} \mathrm{H}\right)=10 \mu\right.$ s, acquisition time: $5 \mathrm{~s}$, relaxation delay $10 \mathrm{~s}$ ) on a Bruker DMX $500 \mathrm{spec}-$ trometer; HDO was used as internal reference: $4.63 \mathrm{ppm}$ ). Solvent suppression was done by the first increment of the preset-NOESY sequence with a mixing time of $1 \mathrm{~ms}$.

\subsection{Fourier transform ion cyclotron resonance (FTICR) mass spectrometry}

High-resolution mass spectra were acquired on a Bruker (Bremen, Germany) APEX-Q ICR-FT/MS equipped with a 12 Tesla superconducting magnet and an APOLLO II electrospray source that was used in negative mode. Freeze-dried samples were dissolved into pure LC/MS grade methanol (Sigma-Aldrich, Seelze, Germany) to a final concentration of $50 \mathrm{mg} \mathrm{L}^{-1}$ and introduced via the micro-electrospray source at a flow rate of $120 \mu \mathrm{L} \mathrm{h}^{-1}$. The nebulizer gas pressure was set to $20 \mathrm{psi}$, and a drying gas pressure to $15 \mathrm{psi}\left(@ 250^{\circ} \mathrm{C}\right)$. Spectra were first externally calibrated on clusters of arginine $\left(10 \mathrm{mg} \mathrm{L}^{-1}\right.$ in methanol) and internally with fatty acids (mass range of 199-367 Da). Calibration errors in the relevant mass range were always below $0.1 \mathrm{ppm}$. The spectra were acquired with a time domain of 4 megawords with a mass range of 150 $2000 \mathrm{~m} / \mathrm{z}$. The spectra were zero filled to a processing size of 4 megawords. Before Fourier transformation of the time-domain transient, a sine apodization was performed.

The calibrated FT-ICR mass spectra were exported as peak lists for all peaks having a signal-to-noise ratio of 2 or greater. A threshold of 3 is more typically used; however, the use of a signal-to-noise threshold of 2 increased the likelihood that low-intensity, ${ }^{13} \mathrm{C}$-containing peaks would not be overlooked. In-house software was developed (Perdue) and used to try to assign molecular formulae to all peaks. The algorithm first converted the experimental mass-tocharge ratio of a negative ion into a mass that was consistent with the assumed charge $(-1$ or -2$)$ and then added the masses of an appropriate number of protons ( 1 or 2 ) to yield the mass of the corresponding uncharged molecule. Submolecular components were then used to build the molecular formulae of uncharged molecules containing $\mathrm{C}$, $\mathrm{H}, \mathrm{O}, \mathrm{N}$, and $\mathrm{S}$. With the exception of $\mathrm{C}$, for which both ${ }^{12} \mathrm{C}$ and ${ }^{13} \mathrm{C}$ are used, only the most abundant isotopes of the elements were employed. When expressed in terms of the components, the molecular formula being assigned to a peak takes the general form of $\mathrm{H}_{2(1-U)}\left({ }^{13} \mathrm{C}_{1}{ }^{12} \mathrm{C}_{-1}\right)_{E^{-}}$ $\left({ }^{12} \mathrm{CH}_{2}\right)_{W} \mathrm{O}_{X}(\mathrm{NH})_{Y} \mathrm{~S}_{Z}$, where $U$ is the moles of unsaturation (rings and/or pi-bonds), $E$ is the moles of a carbon isotope exchange operator, and $W, X, Y$, and $Z$ are ordinary stoichiometric coefficients. The corresponding molecular formula in its more familiar form is ${ }^{13} \mathrm{C}_{E}{ }^{12} \mathrm{C}_{W-E} \mathrm{H}_{2(1-U)+2 W+Y} \mathrm{O}_{X} \mathrm{~N}_{Y} \mathrm{~S}_{Z}$. In this particular analysis, molecular formulae were restricted to those containing only $\mathrm{C}, \mathrm{H}$, and $\mathrm{O}$ (see Section 3.3.6). The stoichiometric 
coefficient for isotope exchange was varied systematically $(0 \leqslant E \leqslant 1)$, and the other coefficients were varied within constraints arising from the unassigned mass of the molecule until a molecular formula met the following constraints:

- $2 \leqslant \mathrm{H} \leqslant(2 \mathrm{C}+2)$

- $0 \leqslant \mathrm{O} \leqslant(\mathrm{C}+2)$

- mass error $\left(\frac{\mid \text { measured mass-calculated mass } \mid}{\text { measured mass }}\right) \leqslant 0.4 \mathrm{ppm}$

The mass error requirement must be satisfied for both ${ }^{12} \mathrm{C}_{W} \mathrm{H}_{X} \mathrm{O}_{Y}$ and its isotopic complement- ${ }^{13} \mathrm{C}_{1}{ }^{12} \mathrm{C}_{W-1} \mathrm{H}_{X^{-}}$ $\mathrm{O}_{Y}$. The peaks in a mass spectrum were classified into three categories: (1) peaks to which a molecular formula could not be assigned, (2) peaks to which a molecular formula could be assigned to only one member of a complementary isotopic pair, and (3) peaks to which molecular formulae could be assigned to both members of a complementary isotopic pair. Because the likelihood of a correct molecular formula is greatest for the third category of peaks, only paired peaks were used to analyze FTICR-MS results, unless stated otherwise.

\section{RESULTS AND DISCUSSION}

\subsection{Removal of water and sea salts and recovery of DOM}

The volume and conductivity of a seawater sample were recorded manually at irregular intervals during the coupled RO/ED process. The typical results in Fig. 2 illustrate the three phases of the coupled RO/ED process. During the initial ED phase, conductivity decreased from 56 to $15 \mathrm{mS} \mathrm{cm}^{-1}$. The volume decreased concomitantly from 200 to $180 \mathrm{~L}$, even though the RO system was not pressurized to remove water. Because conductivity is an intensive property, the quantity of sea salts removed from the sample is best estimated from the change in the product of conductivity and volume, which is an extensive property. Using this approach, $76 \%$ of sea salts and $20 \mathrm{~L}$ of water were removed from a $200 \mathrm{~L}$ sample of seawater during the initial ED phase - a ratio of approximately 6.8 moles of water

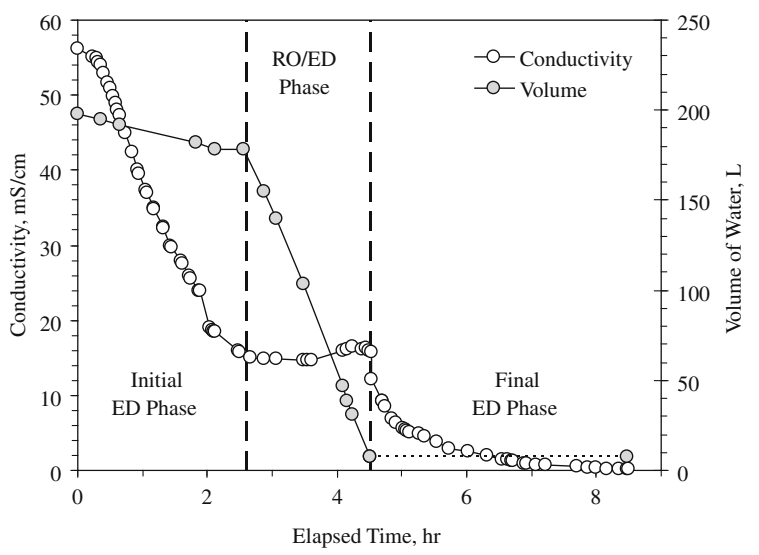

Fig. 2. Typical removal of conductivity and water during the coupled RO/ED process. per mole of ions. This ratio is similar to the hydration numbers of major ions (Onori, 1988), indicating that most, if not all, of the water that is removed during the initial ED phase was in the form of hydrated ions. Whatever the mechanism, $10 \%$ of the water and $76 \%$ of the sea salts were removed from the sample at the end of the initial ED phase (Fig. 2).

Water was removed at an approximately constant rate during the RO/ED phase - a consequence of the nearly constant conductivity (and thus osmotic pressure) that was maintained by balanced desalting by ED. At the end of the RO/ED phase, more than $95 \%$ of the water and approximately $99 \%$ of the sea salts (the product of conductivity and volume) were removed. During the final ED phase, conductivity was decreased from 15 to either $10 \mathrm{mS} \mathrm{cm}^{-1}$ or $0.1 \mathrm{mS} \mathrm{cm}{ }^{-1}$ for samples processed using either continuous or pulsed ED, respectively. When pulsed ED was used, more than $95 \%$ of the water and more than $99.995 \%$ of the sea salts were removed at the end of the final ED phase.

Descriptive statistics for the procedural blank (S706-0) and the 16 samples are given in Table 2. Yields of DOC were calculated from Eq. (1), and the $\mathrm{DOC}_{\text {sacrificed }}$ term in Eq. (1) was calculated as the product of "Sacrificed DOC" and the volume of the initial sample in Table 2. The procedural blank gained around $3 \mu \mathrm{mol} \mathrm{L}{ }^{-1}$ of DOC during the $\mathrm{RO} / \mathrm{ED}$ process, which is not considered to be significant relative to the initial DOC concentrations $52-412 \mu \mathrm{mol} \mathrm{L}^{-1}$ in the seawater samples. The yield of DOC for the 16 seawater samples ranged from $61 \%$ to $95 \%$ and averaged $75 \pm 12 \%$.

An average yield of $75 \%$ represents a major improvement in the ability to isolate DOM from seawater. An average of $30 \%$ of DOC has been recovered by tangential-flow ultrafiltration from 74 surface and deep ocean waters having salinities of $\geqslant 30$, with a slightly greater yield in surface waters (Benner et al., 1997; Aluwihare et al., 1997; Hernes and Benner, 2002; Benner and Opsahl, 2001; Guo et al., 1995, 1996, 2003; Guo and Santschi, 1997). An average of $16 \%$ of DOC has been recovered by XAD- 2 and XAD- 8 resins (including studies where these resins were used in tandem with XAD-4 resin) from 25 surface and deep ocean waters having salinities of $\geqslant 30$, with a slight tendency for greater recoveries in deep waters (Stuermer and Harvey, 1977; Harvey et al., 1983; Fu and Pocklington, 1983; Meyers-Schulte and Hedges, 1986; Druffel et al., 1992; Hedges et al., 1992). An average of around $33 \%$ of DOC has been recovered by $\mathrm{C}_{18}$ adsorbent from 20 surface and deep ocean waters having salinities of $\geqslant 30$, (Mills and Quinn, 1981; Amador et al., 1990; Koch et al., 2005; Simjouw et al., 2005; Dittmar et al., 2008). An average of $43 \%$ of DOC has been recovered by PPL (a styrene-divinylbenzene polymer) cartridges from 12 surface and deep ocean waters. Much higher yields $(62-65 \%)$ were obtained from saline waters in coastal zones. Neglecting the latter samples, the weighted-average yield of DOC from UF, XAD resins, $\mathrm{C}_{18}$, and PPL is $29 \%$, which is approximately one-third the average yield that was obtained using the coupled RO/ED process.

Because the yield of DOM that is obtained using the $\mathrm{RO} / \mathrm{ED}$ method is much greater than yields that are typi- 
Table 2

Processing of a procedural blank (S706-0) and seawater samples by reverse osmosis/electrodialysis.

\begin{tabular}{|c|c|c|c|c|c|c|c|c|c|c|}
\hline \multirow[t]{2}{*}{ Site } & \multicolumn{3}{|c|}{ Initial sample } & \multirow{2}{*}{$\begin{array}{l}\text { Sacrificed } \\
\text { DOC }\end{array}$} & \multicolumn{3}{|c|}{ Final sample } & \multicolumn{3}{|c|}{ Rinse sample } \\
\hline & Vol. & Cond. & DOC & & Vol. & Cond. & DOC & Vol. & DOC & Yield \\
\hline S706-0 & 198.4 & 0.029 & 5.4 & 0.2 & 6.17 & 0.687 & 199 & 2.50 & 164 & 157 \\
\hline S706-1 & 198.4 & 47.1 & 83.0 & 1.0 & 6.28 & 6.3 & 1963 & 4.90 & $\# \mathrm{~N} / \mathrm{A}$ & 76 \\
\hline S706-2 & 198.4 & 49.7 & 57.4 & 0.9 & 6.77 & 9.3 & 1179 & 6.85 & 369 & 94 \\
\hline S706-3 & 198.4 & 44.2 & 83.9 & 1.0 & 6.84 & 9.0 & 1774 & 4.60 & 120 & 77 \\
\hline S706-4 & 198.4 & 49.8 & 86.6 & 1.6 & 6.30 & 8.8 & 1699 & 5.00 & 65 & 66 \\
\hline S706-5 & 198.4 & 51.2 & 52.5 & 0.6 & 8.14 & 8.8 & 1207 & 4.90 & $\# \mathrm{~N} / \mathrm{A}$ & 95 \\
\hline S706-6 & 198.4 & 53.2 & 78.5 & 0.9 & 5.90 & 10.8 & 1706 & 3.10 & 121 & 68 \\
\hline S706-7 & 198.4 & 52.6 & 85.7 & 1.1 & 7.00 & 9.5 & 1418 & 2.50 & 141 & 61 \\
\hline S706-8 & 198.4 & 51.2 & 79.1 & 3.1 & 8.48 & 0.187 & 1201 & $\# \mathrm{~N} / \mathrm{A}$ & $\# \mathrm{~N} / \mathrm{A}$ & 68 \\
\hline S706-9 & 394.1 & 52.6 & 74.2 & 1.1 & 9.57 & 10.9 & 2154 & 5.20 & 94 & 73 \\
\hline S706-10 & 198.4 & 44.8 & 412.0 & 5.3 & 8.84 & 11.4 & 8596 & 5.20 & $\# \mathrm{~N} / \mathrm{A}$ & 94 \\
\hline S1006-1 & 103.7 & 47.2 & 78.5 & 4.1 & 6.44 & 0.096 & 938 & 2.56 & 418 & 92 \\
\hline S1006-2 & 198.4 & 51.3 & 79.4 & 3.2 & 5.89 & 0.050 & 1529 & 3.20 & 485 & 70 \\
\hline S1006-3 & 198.4 & 54.3 & 74.6 & 4.4 & 4.78 & 0.096 & 1736 & 2.49 & 688 & 72 \\
\hline S1006-4 & 198.4 & 56.2 & 65.9 & 2.4 & 7.27 & 0.099 & 1092 & 2.97 & 393 & 72 \\
\hline S1006-5 & 198.4 & 56.4 & 67.2 & 3.1 & 4.97 & 0.075 & 1316 & 2.71 & 490 & 62 \\
\hline S1006-6 & 100.5 & 47.7 & 349.3 & 9.9 & 8.99 & 0.052 & 2082 & 2.85 & 738 & 61 \\
\hline
\end{tabular}

* Vol, Cond., and DOC are in units of $\mathrm{L}, \mathrm{mS} \mathrm{cm}^{-1}$, and $\mu \mathrm{mol} / \mathrm{L}$, respectively. Yield is a percentage.

cally obtained using solid-phase adsorbents or cross-flow ultrafiltration, isolated samples are more likely to be representative of marine DOM. One indication that this might be the case is found in the recent work of Diaz et al. (2008), who reported that samples isolated from seawater in $70 \%$ yield using the RO/ED method contained significant concentrations of polyphosphates, which had not previously been observed in isolated samples of marine DOM.

\subsection{Mass balance for DOM in the coupled RO/ED process}

The average yield of $75 \%$ when DOM is isolated using the coupled RO/ED process includes both the DOM that remains in solution at the end of the final ED phase and the DOM that is recovered from the RO and ED membranes when they are washed for three minutes with $0.01 \mathrm{M} \mathrm{NaOH}$. The average loss of $25 \%$ of DOC during the coupled $\mathrm{RO} / \mathrm{ED}$ process cannot be explained by losses of DOC across the RO membrane and into the RO permeate solution or by losses of DOC across the ED membranes and into the concentrate solution. A careful analysis of intermediate DOC concentrations in the diluate, concentrate, electrode rinse, and RO permeate solutions at various points in each phase of the RO/ED process has revealed that most of the loss of DOC occurred during the final ED phase, when DOC concentration was at a maximum and conductivity decreased to less than $1 \mathrm{mS} \mathrm{cm}^{-1}$ (Gurtler et al., 2008). All evidence suggests that the unrecovered DOM was adsorbed to the RO and ED membranes and was not fully desorbed during the $\mathrm{NaOH}$ rinse. The unrecovered adsorbed DOM did not seem to carry over to the next processed sample, because yields were always less than $100 \%$. It was presumably flushed from the system when the entire RO/ED system was washed with a $50 \mathrm{~L}$ aliquot of the next seawater sample, but the wash solutions were unfortunately discarded without taking samples for measurement of DOC. This hypothesis is supported by several observa- tions that the adsorption of DOM on both RO and ED membranes is diminished in the presence of $\mathrm{NaCl}$ (Koprivnjak et al., 2006; Kim et al., 2002; Lee and Elimelech, 2007).

Unlike the seawater samples, the procedural blank actually gained a small amount of DOC during the RO/ED process. Because the procedural blank was RO permeate water, the RO/ED system was flushed initially with $50 \mathrm{~L}$ of RO permeate water, which has a very low conductivity and DOC concentration. Given the possibly important role of $\mathrm{NaCl}$ in desorbing DOM from membranes, it is likely that adsorbed DOM from the previous seawater sample was incompletely desorbed during the $50 \mathrm{~L}$ wash. Residual adsorbed DOM could have ultimately desorbed into the $200 \mathrm{~L}$ procedural blank, causing its DOC concentration to increase. The UV/visible spectrum of the procedural blank should then qualitatively resemble that of the previously isolated sample of marine DOM (see Section 3.3.2).

\subsection{Characterization of RO/ED samples by chemical and spectroscopic methods}

\subsubsection{Rationale for selection of RO/ED samples for further characterization}

Five representative samples from coastal, Gulf Stream, and non-coastal seawater were selected for characterization by both chemical and spectroscopic methods. The principal criterion for selection was the degree to which a sample had been desalted. Only one sample from the July, 2006 cruise (S706-8) was desalted at sea to a comparable level of $0.2 \mathrm{mS} \mathrm{cm}{ }^{-1}$. One non-coastal sample from the July, 2006 cruise (S706-1) was more completely desalted by ED in the laboratory. All samples collected in the October, 2006 cruise were desalted to a conductivity of $0.1 \mathrm{mS} \mathrm{cm}^{-1}$ or less, and three of those samples (S1006-3, S1006-4, and S1006-6) were selected for detailed characterization. 


\subsubsection{UV-visible absorbance spectrometry}

Exponential fits of $a(\lambda)$ versus $\lambda$ for the five RO/ED samples yielded the values of $S_{290-350}$ and $r^{2}$ in Table 3 . The high values of $r^{2}$ indicate that the exponential model in Eq. (3) was appropriate for description of these data sets. For the four RO/ED samples that were collected from the open ocean and Gulf Stream, $S_{290-350}$ values agree well with the published range of 0.020 to 0.037 for the open ocean (Kitidis et al., 2006). SUVA 300 values for those samples (Table 3) are consistent with the results of Kitidis et al. (2006), assuming that DOC concentrations in that study were close to $1 \mathrm{mg} \mathrm{L}^{-1}$. The spectral slope parameter $\left(S_{290-350}\right)$ for the coastal sample (S1006-6) was close to the lower limit of the range reported by Kitidis et al. (2006). Not unexpectedly, the SUVA 300 value for the coastal sample was much greater than those of the other RO/ED samples, reflecting a significant input of terrestrially-derived organic matter to the coastal ocean.

The UV/visible spectra of the RO/ED samples and their respective source seawaters were also compared directly in plots of $a(\lambda) / a(290 \mathrm{~nm})$ versus wavelength that are given in Fig. 3. With the exception of the coastal sample (S1006-6), the comparison is limited by the low absorbance (in a $1-\mathrm{cm}$ cell) of the source seawaters over the range of 290-350 nm. Nonetheless, the results in Fig. 3 are very

Table 3

Optical properties of RO/ED samples of marine DOM.

\begin{tabular}{llll}
\hline Sample & $S_{290-350}$ & $r^{2}$ & SUVA $_{300}$ \\
\hline S706-1 & 0.034 & 0.982 & 0.099 \\
S706-8 & 0.032 & 0.977 & 0.399 \\
S1006-3 & 0.029 & 0.966 & 0.228 \\
S1006-4 & 0.032 & 0.942 & 0.276 \\
S1006-6 & 0.021 & 1.000 & 3.059 \\
\hline
\end{tabular}

encouraging, indicating that the RO/ED samples probably contain a representative distribution of chromophores. For the coastal sample (S1006-6), the normalized spectra of the isolated sample and its source water are essentially indistinguishable between 260 and $420 \mathrm{~nm}$, confirming that a representative fraction of the chromophores from the original $\mathrm{DOM}$ in the source seawater were isolated in that RO/ ED sample. A comparable plot for the initial and final solutions from the procedural blank is also included in Fig. 3. In this case, the "initial" solution is $200 \mathrm{~L}$ of RO permeate water that had been recirculated through the RO/ED system for ten minutes before taking a sample. When compared with the other spectra in Fig. 3, the UV/visible spectra of the initial solution and (to a lesser extent) the final solution lend support to the previous conclusion that desorption of previously adsorbed marine DOM from the RO and ED membranes was mainly responsible for the increase in DOC during processing of the procedural blank.

Of the other methods used to isolate marine DOM, ultrafiltration is most closely related to $\mathrm{RO} / \mathrm{ED}$, in that the separation of water and inorganic salts from DOM is achieved by physical means. Several authors have reported that fairly similar percentages of DOC and UV absorbance are recovered by ultrafiltration (e.g., Amador et al., 1990; Simjouw et al., 2005), with slightly better recovery of UV absorbance than DOC. Solid-phase extractions using $\mathrm{XAD}$ resins and $\mathrm{C}_{18}$ adsorbents are chemically based methods of separation of DOM from water and inorganic salts, and these methods yield isolated samples of marine DOM that are enriched in chromophores and fluorophores (Amador et al., 1990; Obernosterer and Herndl, 2000; Simjouw et al., 2005).

\subsubsection{Molar $C / N$ ratios}

A further test of the degree to which the RO/ED samples are representative of marine DOM is provided by anal-
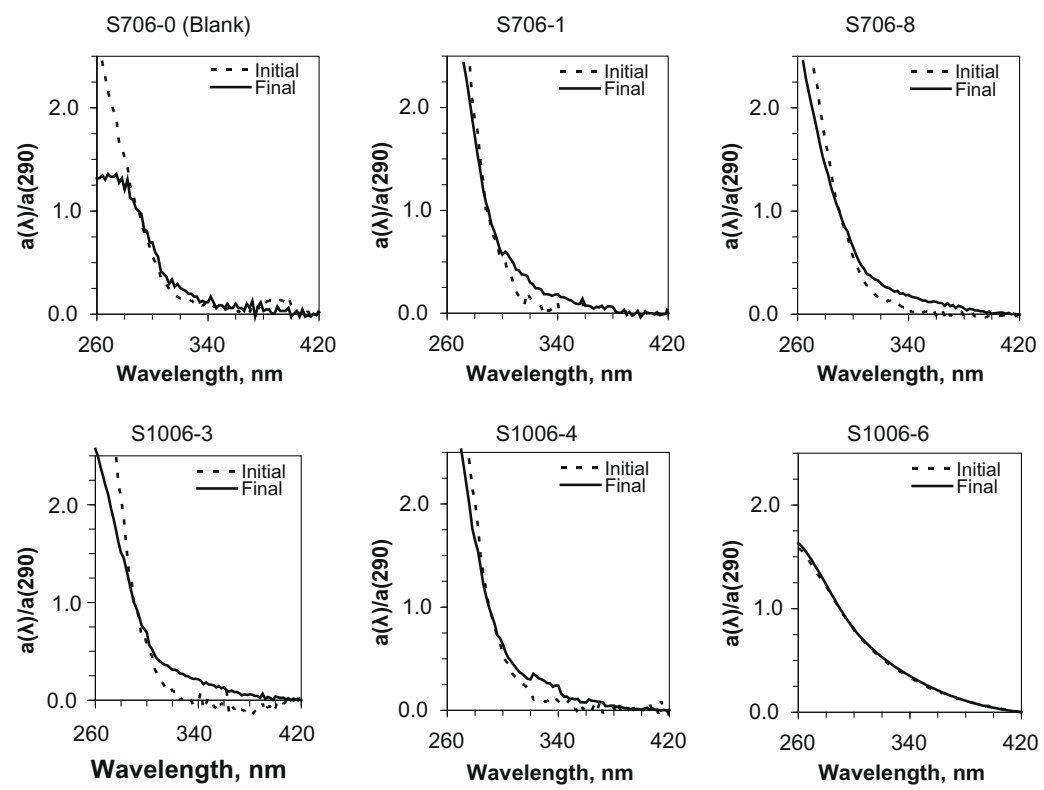

Fig. 3. Normalized absorption coefficients $(\mathrm{a}(\lambda) / \mathrm{a}(290))$ for the procedural blank and five RO/ED samples of marine DOM. 
ysis of molar C/N ratios. Bronk (2002) has tabulated molar $\mathrm{C} / \mathrm{N}$ ratios for surface ocean water $(13.6 \pm 2.8)$, for deep ocean waters $(14.7 \pm 2.8)$, coastal ocean waters and continental shelves $(17.7 \pm 4.3)$. The large data sets of the Hawaii Ocean Time-series (HOT) and Bermuda Atlantic Time-series Study (BATS) for DOC and dissolved organic nitrogen (DON) were also used to estimate molar $\mathrm{C} / \mathrm{N}$ ratios for surface $(\leqslant 200 \mathrm{~m})$ and deep $(>200 \mathrm{~m})$ ocean water. The long-term average molar $\mathrm{C} / \mathrm{N}$ ratios in surface and deep ocean waters were $16.0 \pm 2.4$ and $17.4 \pm 5.8$, respectively, at the HOT site and $13.3 \pm 2.0$ and $13.1 \pm 2.9$, respectively, at the BATS site.

Results for the five RO/ED samples of marine DOM are in Table 4. Measured mass percentages of $\mathrm{C}$ and $\mathrm{N}$ confirm that isolated, freeze-dried RO/ED samples of marine DOM contain a high percentage of inorganic matter. Fortunately, the content of DOM in the freeze-dried samples $(12-50 \%$, assuming that marine DOM contains $50 \% \mathrm{C}$ ) was adequate for all of the analytical methods that were used to characterize these samples. The tabulated $\mathrm{C} / \mathrm{N}$ values are very consistent with the data from Bronk (2002), the HOT site, and the BATS site. Molar $\mathrm{C} / \mathrm{N}$ ratios decreased with increasing distance from the coast (see Fig. 1), which is analogous to the trend in $\mathrm{SUVA}_{300}$ that was discussed previously. Both trends illustrate the diminishing contribution of terrestrially derived DOM to marine DOM samples with increasing distance from land. It can be concluded that DOC and DON are isolated in approximately the same proportions that they occur in seawater. It follows that the average yield of DON in the coupled RO/ED process is around $75 \%$.

Ultrafiltration has consistently been shown to recover samples whose molar $\mathrm{C} / \mathrm{N}$ ratios are in reasonable agreement with those of marine DOM in the source seawaters (Benner et al., 1992, 1997, 2005; Benner and Opsahl, 2001; Guo et al., 2003; Sannigrahi et al., 2005). This is not the case for chemically-based isolation methods. Druffel et al. (1992) reported an average $\mathrm{C} / \mathrm{N}$ ratio of $46.8 \pm 5.9$ for 10 samples of marine DOM that were isolated by adsorption on either XAD-2 or XAD-8 resin and elution from the resin with $\mathrm{NaOH}$. Using XAD-8 resin and $\mathrm{NaOH}$, Hedges et al. (1992) isolated four samples of marine DOM having an average molar $\mathrm{C} / \mathrm{N}$ ratio of $40.4 \pm 5.6$. Interestingly, Druffel et al. (1992) also used XAD-4 resin to process the DOM that was not adsorbed by XAD-8 resin. For six seawater samples, the fraction of DOM that was retained by the XAD-4 resin had an average molar $\mathrm{C} / \mathrm{N}$ ratio of $21.5 \pm 2.2$, which is much closer to $\mathrm{C} / \mathrm{N}$ ratios of marine DOM in seawater. Koch et al. (2005) used $\mathrm{C}_{18}$

Table 4

Mass percentages of $\mathrm{C}$ and $\mathrm{N}$ and molar $\mathrm{C} / \mathrm{N}$ ratios of $\mathrm{RO} / \mathrm{ED}$ samples of marine DOM.

\begin{tabular}{lrrr}
\hline Sample & \multicolumn{1}{c}{$\%$} & $\% \mathrm{~N}$ & $\mathrm{C} / \mathrm{N}$ \\
\hline S706-1 & 14.13 & 1.06 & 15.6 \\
S706-8 & 6.84 & 0.45 & 17.7 \\
S1006-3 & 6.31 & 0.42 & 17.5 \\
S1006-4 & 10.16 & 0.65 & 18.2 \\
S1006-6 & 24.91 & 1.53 & 19.0 \\
\hline
\end{tabular}

adsorbent to concentrate DOM from the Weddell Sea. They recovered $24 \pm 6 \%$ of DOC from six sampling sites, and the isolated DOM had an average $\mathrm{C} / \mathrm{N}$ ratio of 35.6.

\subsection{4. ${ }^{13}$ C NMR spectrometry}

The CPMAS ${ }^{13} \mathrm{C}$ NMR spectra of the five RO/ED samples of marine DOM are in Fig. 4. All the spectra were normalized to the intensity of the main peak for alkoxy $\mathrm{C}$ at a chemical shift of approximately $70 \mathrm{ppm}$. There was insufficient sample from S706-1 to obtain a spectrum with good signal-to-noise ratio, so the results are only approximate (the solid, heavy gray line in Fig. 4). If the peak at $70 \mathrm{ppm}$ is mainly due to carbohydrates, then a peak for the anomeric carbon of carbohydrates should be found at approximately $100 \mathrm{ppm}$. Indeed, the four good-quality spectra have nearly identical peaks at both $70 \mathrm{ppm}$ and approximately $100 \mathrm{ppm}$. The average ratio of the integrated peak areas of the 70 and $100 \mathrm{ppm}$ peaks (integrated from 60-95 ppm and from 95-110 ppm, respectively) is slightly greater than $6: 1$, which is higher than expected for a mixture of hexoses and pentoses, for which the peak area ratio should lie between 5:1 (hexoses) and 4:1 (pentoses). If the peak at $100 \mathrm{ppm}$ is entirely due to carbohydrates, then at least $1 / 6$ of alkoxy $\mathrm{C}$ must be in structural moieties other than sugars, e.g., alkyl esters, ethers, and alcohols.

Among the four samples for which good-quality spectra were obtained, the greatest differences in peak intensity are found in the ranges of 0-60 ppm (alkyl C), 110-160 ppm (aromatic C), and 160-190 ppm (carboxyl C). The spectrum of the coastal sample (S1006-6) has the strongest peak intensity in all of these regions, indicating that this sample contains a lower percentage of carbohydrates than the noncoastal samples. The greater aromaticity of the coastal sample is consistent with the earlier discussion of $\mathrm{SUVA}_{300}$, which is also significantly greater for this sample. The sample which was collected in the Gulf Stream at the depth of the CDOM maximum (S1006-4, $84 \mathrm{~m}$ ) also has relatively strong peak intensity in the alkyl $\mathrm{C}$ region of the spectrum. Other than the relatively minor differences that have been highlighted here, the ${ }^{13} \mathrm{C}$ NMR spectra of the RO/ED samples are remarkably consistent.

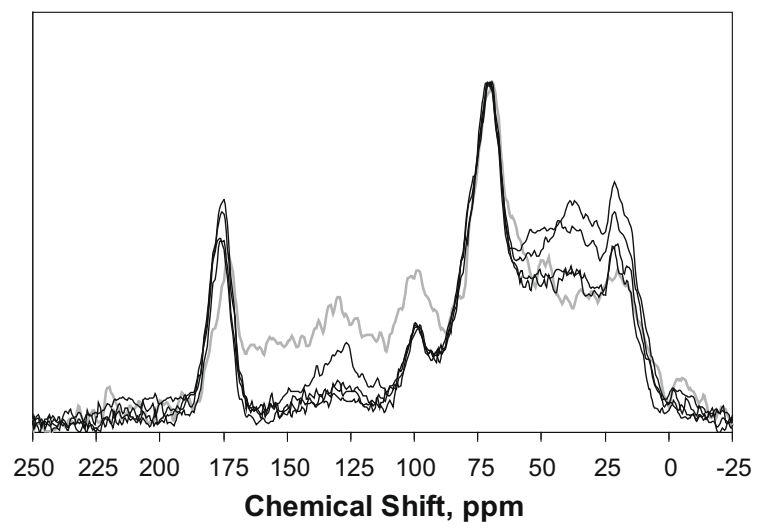

Fig. 4. CPMAS ${ }^{13} \mathrm{C}$ NMR spectra of five RO/ED samples of marine DOM (the gray line is for S706-1). 
The ranges of chemical shift within which the ${ }^{13} \mathrm{C}$ NMR spectra were integrated for five structural categories of organic $\mathrm{C}$ and the resulting carbon distributions for the five $\mathrm{RO} / \mathrm{ED}$ samples of marine DOM are in Table 5. As noted earlier, the spectrum of the S706-1 sample is noisy and possibly non-representative due to the small quantity of sample that was available for the measurement. The integrated ${ }^{13} \mathrm{C}$ NMR peak areas of the other samples are highly consistent. Table 5 also includes integrated peak areas for ultrafiltered dissolved organic matter (UDOM) from both surface and deep waters, for marine humic acids (HA) and fulvic acids (FA) that were isolated using XAD resins from both surface and deep waters, and for median samples of terrestrially derived HA, FA, and natural organic matter (NOM).

Although deeper samples were isolated by the RO/ED method (Table 2), none of the samples in Table 5 is from deeper than $100 \mathrm{~m}$. Accordingly, the RO/ED samples in Table 5 are most appropriately compared with samples that were collected by other methods from surface or near-surface waters. The RO/ED samples contain much more alkyl $\mathrm{C}$ and much less alkoxy $\mathrm{C}$ than surface UDOM. In contrast, the carbon distributions of RO/ED samples are within the (admittedly large) range of results for UDOM from deep ocean waters. The RO/ED samples contain slightly less alkyl $\mathrm{C}$ and much more alkoxy $\mathrm{C}$ than $\mathrm{HA}$ and FA that are isolated from ocean waters using the chemically-based
XAD method, by which compositionally similar samples of DOM are isolated from both surface and deep ocean waters. The $\mathrm{RO} / \mathrm{ED}$ samples contain much more alkyl $\mathrm{C}$ and alkoxy $\mathrm{C}$ than FA, HA, and NOM from freshwaters. Terrestrially-derived samples, in turn, contain much more aromatic $\mathrm{C}$ and carboxyl $\mathrm{C}$ than the $\mathrm{RO} / \mathrm{ED}$ samples. Although not based directly on this research, one cannot help but notice the intriguingly similar distribution of carbon (by ${ }^{13} \mathrm{C}$ NMR spectrometry) in the deep UDOM sample of Benner et al. (1992) and freshwater organic matter. Perhaps this distribution of carbon is a compositional signature of biologically refractory DOM, even if the two materials are derived from different primary sources.

Further analysis of the ${ }^{13} \mathrm{C}$ NMR spectra of the RO/ED, $\mathrm{UF}$, and XAD samples of marine DOM is based on average spectra for the three types of samples. The experimental spectra of S706-8, S1006-3, and S1006-4 were averaged to obtain the ${ }^{13} \mathrm{C}$ NMR spectrum of an average RO/ED sample from non-coastal surface seawater. The ${ }^{13} \mathrm{C}$ NMR spectrum of an average UF sample was calculated by digitizing and averaging spectra of non-coastal surface ocean DOM samples (Benner et al., 1992; Sannigrahi et al., 2005). The ${ }^{13} \mathrm{C}$ NMR spectrum of an average XAD sample was calculated by digitizing and averaging published spectra of DOM samples isolated using XAD resins from coastal seawater (Wilson et al., 1983) and non-coastal seawater (Mal-

Table 5

Carbon distribution (\%) from CPMAS ${ }^{13} \mathrm{C}$ NMR spectrometry for marine DOM isolated by the coupled RO/ED process, ultrafiltration, and $\mathrm{XAD}$ resins, and for freshwater organic matter.

\begin{tabular}{|c|c|c|c|c|c|}
\hline $\begin{array}{l}\text { Chemical shift, ppm } \\
\text { Structural category }\end{array}$ & $\begin{array}{l}0-60 \\
\text { Alkyl }\end{array}$ & $\begin{array}{l}60-110 \\
\text { Alkoxy }\end{array}$ & $\begin{array}{l}110-160 \\
\text { Aromatic }\end{array}$ & $\begin{array}{l}160-190 \\
\text { Carboxyl }\end{array}$ & $\begin{array}{l}\text { 190-220 } \\
\text { Carbonyl }\end{array}$ \\
\hline \multicolumn{6}{|c|}{ Marine DOM isolated using reverse osmosislelectrodialysis } \\
\hline S706-1 (20 m) & 31 & 36 & 19 & 11 & 3 \\
\hline $\mathrm{S} 706-8(20 \mathrm{~m})$ & 39 & 37 & 8 & 13 & 3 \\
\hline $\mathrm{S} 1006-3(20 \mathrm{~m})$ & 40 & 39 & 7 & 12 & 2 \\
\hline S1006-4 (84 m) & 44 & 36 & 7 & 11 & 2 \\
\hline $\mathrm{S} 1006-6(2 \mathrm{~m})$ & 43 & 32 & 10 & 11 & 4 \\
\hline \multicolumn{6}{|c|}{ Marine DOM isolated using ultrafiltration $(U D O M)^{\mathrm{g}}$} \\
\hline $\operatorname{UDOM}(10 \mathrm{~m})^{\mathrm{a}}$ & 25 & 53 & 7 & 12 & 3 \\
\hline UDOM $(20 \mathrm{~m})^{\mathrm{b}}$ & 26 & 66 & 0 & \multicolumn{2}{|c|}{8} \\
\hline UDOM $(4000 \mathrm{~m})^{\mathrm{a}}$ & 30 & 28 & 21 & 16 & 5 \\
\hline UDOM $(4000 \mathrm{~m})^{\mathrm{b}}$ & 46 & 43 & 0 & \multicolumn{2}{|c|}{11} \\
\hline \multicolumn{6}{|c|}{ Marine humic acids (HA) and fulvic acids $(F A)$ isolated using $X A D$ resins ${ }^{\mathrm{g}}$} \\
\hline $\mathrm{HA}+\mathrm{FA}(\text { coastal })^{\mathrm{c}}$ & 48 & 20 & 18 & \multicolumn{2}{|c|}{14} \\
\hline FA $(100 \mathrm{~m})^{\mathrm{d}}$ & 51 & 22 & 12 & \multicolumn{2}{|c|}{15} \\
\hline $\mathrm{HA}+\mathrm{FA}(5 \mathrm{~m})^{\mathrm{e}}$ & 45 & 18 & 18 & 15 & 4 \\
\hline $\mathrm{HA}+\mathrm{FA}(4200 \mathrm{~m})^{\mathrm{e}}$ & 46 & 17 & 19 & 15 & 3 \\
\hline \multicolumn{6}{|c|}{ Freshwater organic matter (median composition) ${ }^{\mathrm{g}}$} \\
\hline Fulvic acids ${ }^{\mathrm{f}}$ & 31 & 23 & 25 & \multicolumn{2}{|l|}{17} \\
\hline Humic acids ${ }^{\mathrm{f}}$ & 25 & 26 & 32 & 14 & 3 \\
\hline $\mathrm{NOM}^{\mathrm{f}}$ & 27 & 24 & 25 & 19 & 5 \\
\hline
\end{tabular}

${ }^{\text {a }}$ Benner et al. (1992).

b Sannigrahi et al. (2005).

${ }^{c}$ Wilson et al. (1983).

${ }^{d}$ Malcolm (1990).

e Hedges et al. (1992).

${ }^{\mathrm{f}}$ Perdue and Ritchie (2003).

g Published peak areas have been normalized to $100 \%$, if necessary. 


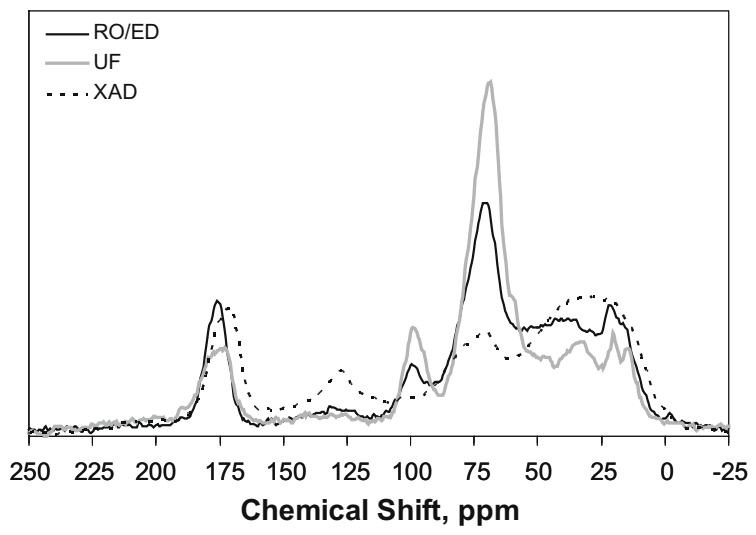

Fig. 5. Averaged CPMAS ${ }^{13} \mathrm{C}$ NMR spectra of marine DOM samples that have been isolated using the coupled RO/ED process, ultrafiltration, and XAD resins.

colm, 1990; Hedges et al., 1992). Prior to averaging peak intensities, the individual spectra were normalized to the same total integrated peak area. The three resulting average spectra are shown in Fig. 5. Across the entire range of chemical shift, the peak intensity for the RO/ED sample tends to be intermediate between the peak intensities for the UF and XAD samples, in effect averaging out the dramatic differences between the spectra of samples isolated by the UF and XAD methods. In fact, most of the characteristics of the average ${ }^{13} \mathrm{C}$ NMR spectrum of $\mathrm{RO} / \mathrm{ED}$ samples are well represented by a $55: 45$ mixture of the average ${ }^{13} \mathrm{C}$ NMR spectra of UF and XAD samples (not shown).

Hertkorn et al. (2006) conducted an interesting computational analysis with ${ }^{13} \mathrm{C}$ NMR spectra of two samples of marine DOM that were isolated by UF from surface and deep ocean waters. They normalized the ${ }^{13} \mathrm{C}$ NMR spectra of surface and deep UDOM samples to the main carbohydrate peak near $70 \mathrm{ppm}$ and calculated a difference spectrum that was attributed to a complex mixture of carboxyl-rich alicyclic molecules (CRAM). CRAM was described as a "major refractory constituent of marine UDOM", and its ${ }^{13} \mathrm{C}$ NMR spectrum is given as the gray line in Fig. 6. For comparative purposes, the average ${ }^{13} \mathrm{C}$ NMR spectra of RO/ED and UF samples of marine DOM (see Fig. 5) were normalized to the main carbohydrate peak at $70 \mathrm{ppm}$ and subtracted to obtain a difference spectrum, assuming that both methods isolate similar mixtures of carbohydrates. Because the RO/ED and UF samples have comparable $\mathrm{C} / \mathrm{N}$ ratios, it is likely that the contribution of peptides is largely cancelled out in the difference spectrum. That difference spectrum is compared in Fig. 6 with the spectrum of CRAM that was published by Hertkorn et al. (2006). Other than the stronger carboxyl peak in the (RO/ED-UF) difference spectrum, there was strong agreement between the spectra.

\subsection{5. ${ }^{1} H$ NMR spectrometry}

The ${ }^{1} \mathrm{H}$ NMR spectra of the five RO/ED samples of marine DOM are given in Fig. 7. All the spectra were normalized to the total peak area within the chemical shift range of $0-10 \mathrm{ppm}$, excluding the region of $4.5-5.0 \mathrm{ppm}$,

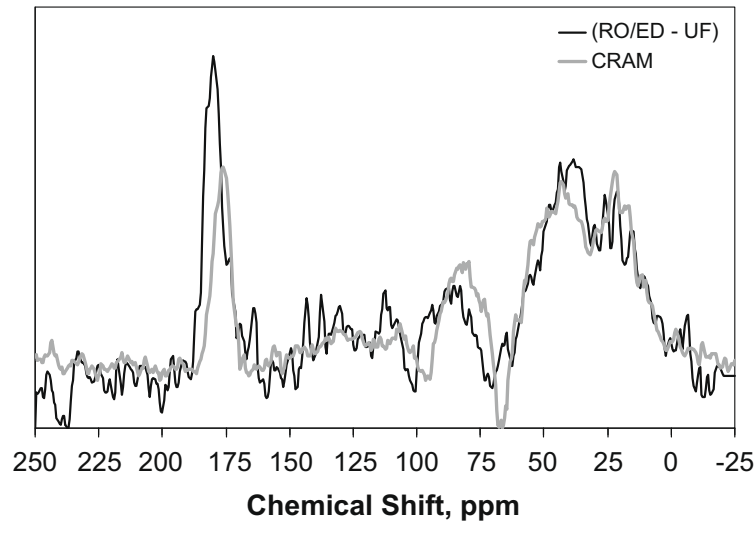

Fig. 6. Comparison of the ${ }^{13} \mathrm{C}$ NMR spectra of CRAM (carboxylrich alicyclic molecules) and the difference spectrum that is calculated from the average spectra of the RO/ED and UF samples. Before subtraction, the average spectra from Fig. 5 were normalized to the same intensity for the main carbohydrate peak at $70-72 \mathrm{ppm}$.

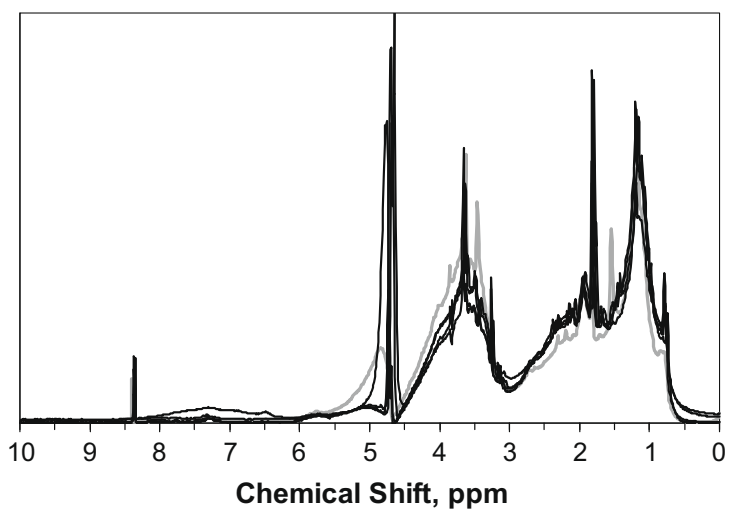

Fig. 7. ${ }^{1} \mathrm{H}$ NMR spectra of five RO/ED samples of marine DOM (the gray line is for S706-1).

which is dominated by the HDO water peak. In Fig. 4, the ${ }^{13} \mathrm{C}$ NMR spectrum of S706-1 was displayed as a solid, heavy gray line to distinguish it from the spectra of the other four samples, because an insufficient amount of that sample was available to obtain a high-quality ${ }^{13} \mathrm{C} \mathrm{NMR}$ spectrum. There was a sufficient amount of the S706-1 sample to obtain a high-quality ${ }^{1} \mathrm{H}$ NMR spectrum. Nonetheless, its spectrum is again shown in gray in Fig. 7, in this case to emphasize its similarity to the ${ }^{1} \mathrm{H}$ NMR spectra of other four samples. The high degree of similarity of the five ${ }^{1} \mathrm{H}$ NMR spectra confirms what the ${ }^{13} \mathrm{C}$ NMR spectra in Fig. 4 could not-that the S706-1 sample is, in fact, quite similar to the other four samples.

Integrated peak areas for the five RO/ED samples of marine DOM are given in Table 6. The ranges of chemical shift within which the spectra were integrated for five structural categories of organic $\mathrm{H}$ are included in Table 6. Alkyl $\mathrm{H}$ is the most common structural category of organic $\mathrm{H}$ in all five RO/ED samples. This category includes protons on alkyl $\mathrm{C}$ that are bonded directly to other alkyl $\mathrm{C}$ and at 
Table 6

Hydrogen distribution (\%) from ${ }^{1} \mathrm{H}$ NMR spectrometry for marine DOM isolated by the coupled RO/ED process.

Chemical shift, ppm 0.5-1.95 1.95-3.1 3.1-4.6 4.7-6.0 6.0-10.0 Structural Alkyl F-Alkyl a Alkoxy Acetal Aromatic category

\begin{tabular}{llllll}
\hline S706-1 $(20 \mathrm{~m})$ & 37 & 20 & 39 & 2 & 2 \\
S706-8 $(20 \mathrm{~m})$ & 45 & 21 & 31 & 2 & 1 \\
S1006-3 $(20 \mathrm{~m})$ & 42 & 22 & 31 & 4 & 1 \\
S1006-4 $(84 \mathrm{~m})$ & 51 & 21 & 27 & 1 & 0 \\
S1006-6 $(2 \mathrm{~m})$ & 42 & 23 & 29 & 1 & 5 \\
\hline
\end{tabular}

${ }^{\mathrm{a}}$ Functionalized alkyl $\mathrm{H}$-in close proximity to carbonyl groups, aromatic rings, etc.

least two carbons away from unsaturated or electronegative groups. The second most abundant category of organic $\mathrm{H}$ in all five samples is alkoxy $\mathrm{H}$, which includes protons on alkyl $\mathrm{C}$ that are bonded directly to $\mathrm{O}$ (or $\mathrm{N}$ ). The third most abundant form of organic $\mathrm{H}$ is functionalized alkyl $\mathrm{H}$, which includes protons on alkyl $\mathrm{C}$ that are bonded directly to aromatic rings, carbonyl groups, carboxyl groups, etc. Only a very small percentage of organic $\mathrm{H}$ occurs as acetal $\mathrm{H}$ or aromatic $\mathrm{H}$ in the RO/ED samples. Even so, the clearly higher percentage of aromatic $\mathrm{H}$ in the coastal sample (S1006-6) agrees with its higher percentage of aromatic C (Table 5).

Further analysis of the ${ }^{1} \mathrm{H}$ NMR spectra of the RO/ED, $\mathrm{UF}$, and XAD samples of marine DOM is based on average spectra for the three types of samples. The experimental spectra of S706-8, S1006-3, and S1006-4 were averaged to obtain the ${ }^{1} \mathrm{H}$ NMR spectrum of an average RO/ED sample from non-coastal surface seawater. The ${ }^{1} \mathrm{H}$ NMR spectrum of an average UF sample was calculated by digitizing and averaging published spectra of surface ocean DOM samples (Aluwihare et al., 1997; Hertkorn et al., 2006). The ${ }^{1} \mathrm{H}$ NMR spectrum of an average sample of marine DOM that is isolated using solid-phase extractions (SPE) was calculated by digitizing and averaging published spectra of two DOM samples isolated using XAD resins from seawater (Wilson et al., 1983; Harvey et al., 1983) and one sample that was isolated using PPL adsorbent, which, like XAD-2, is a styrene divinyl benzene polymer (Dittmar et al., 2008). Prior to averaging peak intensities, the individual spectra were normalized to the same total integrated peak area from 0.0 to $10.0 \mathrm{ppm}$ (excluding the peak intensity between 4.5 and $5.0 \mathrm{ppm}$, which is strongly affected by the signal from HDO). The three resulting average spectra for samples of marine DOM that were isolated using RO/ED, UF, and SPE are shown in Fig. 8.

As was seen in the average ${ }^{13} \mathrm{C}$ NMR spectra in Fig. 5, the peak intensity for the RO/ED sample is generally intermediate between the peak intensities for the UF and SPE samples across the entire range of chemical shift, in effect averaging out the dramatic differences between the spectra of samples isolated by the UF and SPE methods. The RO/ED spectrum does have more peak intensity at $1.2 \mathrm{ppm}$-the chemical shift range for protons attached to alkyl C that are bonded directly to other alkyl C and at least two carbons away from unsaturated or electronegative

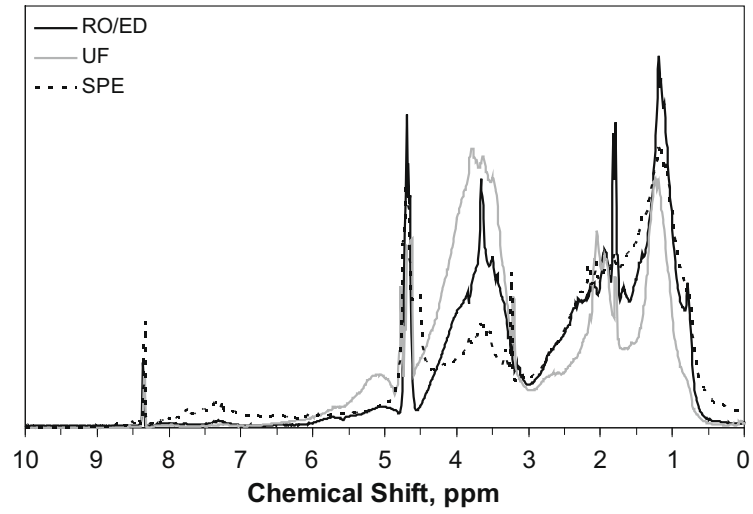

Fig. 8. Averaged ${ }^{1} \mathrm{H}$ NMR spectra of marine DOM samples that have been isolated using the coupled $\mathrm{RO} / \mathrm{ED}$ process, ultrafiltration, and solid-phase extractions.

groups-than either of the other average spectra. The average ${ }^{1} \mathrm{H}$ NMR spectrum of RO/ED samples is rather well described by a 36:64 mixture of the average ${ }^{1} \mathrm{H}$ NMR spectra of UF and SPE samples (not shown). It was noted earlier that the average ${ }^{13} \mathrm{C}$ NMR spectrum of $\mathrm{RO} / \mathrm{ED}$ samples is best described by a 55:45 mixture of the average spectra of UF and XAD samples. This difference in mixing ratios should not be over-interpreted because completely different samples were used to calculate the average ${ }^{1} \mathrm{H}$ and ${ }^{13} \mathrm{C}$ NMR spectra for both the UF and SPE samples.

\subsubsection{Fourier transform ion cyclotron resonance (FTICR) mass spectrometry}

FTICR-MS offers an analytical window through which the compositional features of DOM may be observed with unprecedented resolution. FTICR mass spectra were acquired for the five RO/ED samples of marine DOM and four other samples:

- surface UDOM that was isolated at Station ALOHA by Benner et al. (1997) and recently characterized by Hertkorn et al. (2006),

- deep UDOM that was isolated at Station ALOHA by Benner et al. (1997) and recently characterized by Hertkorn et al. (2006),

- Suwannee River NOM (IHSS No. 1R101N), which was isolated using RO,

- Suwannee River fulvic acid (IHSS No. 2S101F), which was isolated using XAD-8 resin.

These four samples collectively represent three sources (surface ocean, deep ocean, and blackwater river) and three methods of isolation (RO, UF, and XAD-8 resin). Their FTICR mass spectra provide valuable insight for interpretation of the mass spectra of the five RO/ED samples.

For the nine mass spectra that are presented here, the average broadband resolving power of the mass spectrometer in the mass-to-charge $(\mathrm{m} / \mathrm{z})$ range of 150-800 (which included an average of $94 \%$ of peaks and $98 \%$ of peak intensity) is $530,000 \pm 60,000$. In a narrow $\mathrm{m} / \mathrm{z}$ range of $399-401$, the average broadband resolving power is $440,000 \pm 30,000$. With such high resolution, molecular 
masses can be determined with high accuracy, and unique molecular formulae can often be assigned.

Many preliminary tests were conducted in which the FTICR-MS data were analyzed with/without N. Although $36 \%$ more molecular formulae can be assigned when one $\mathrm{N}$ is included, only $3.6 \%$ more complementary isotopic pairs are found (see Section 2.11). For this reason, each mass spectrum was processed to obtain molecular formulae based on ${ }^{13} \mathrm{C},{ }^{12} \mathrm{C},{ }^{1} \mathrm{H}$, and ${ }^{16} \mathrm{O}$. Unless clearly stated to the contrary, all subsequent tables, figures, and discussion of FTICR-MS data refer to the paired peaks, i.e., those for which a valid chemical composition was assigned to both members of a complementary isotopic pair (see Section 2.11).

A summary of major characteristics of the nine mass spectra is in Table 7. The major patterns in Table 7 are the similarity of the statistical results for the non-coastal $\mathrm{RO} / \mathrm{ED}$ samples and the non-coastal UF samples from Station ALOHA, the approximately twofold higher statistical results for the terrestrial samples from the Suwannee River, and the intermediate character of the coastal RO/ED sample (S1006-6). Several percentages in Table 7 are based on the full data sets of peaks having $\mathrm{S}: \mathrm{N} \geqslant 2$ ( $\mathrm{S}: \mathrm{N}$ is the signal-to-noise ratio). Somewhat higher percentages can be obtained, if calculated relative to the more commonly used subset of peaks with $\mathrm{S}: \mathrm{N} \geqslant 3$, and the peak counts and intensities of that subset of peaks are also in Table 7. Considering all peaks having $S: N \geqslant 2$, the mass spectra of the four non-coastal RO/ED samples and the two UF samples have an average of $15,000 \pm 5100$ peaks. Assigned peaks and paired peaks account for $48 \pm 5 \%$ and $35 \pm 5 \%$ of total peak intensity, respectively, and compounds having $\mathrm{H} /$ $\mathrm{C}<1$ account for only $0.17 \pm 0.14 \%$ of the peak intensity of paired peaks. Singly-charged peaks accounted for $94 \pm 12 \%$ of total peak intensity. The FTICR mass spectra of the terrestrially-derived Suwannee River samples and the $\mathrm{RO} / \mathrm{ED}$ sample from the coastal ocean yielded significantly more peaks $(28,000 \pm 1900)$, assigned and paired peaks accounted for much greater percentages of total peak intensity (78 $\pm 10 \%$ and $67 \pm 9 \%$, respectively), singly-charged peaks accounted for a similar percentage of total peak intensity ( $97 \pm 2 \%$ ), and compounds having $\mathrm{H} / \mathrm{C}<1$ accounted for $31 \pm 20 \%$ of the peak intensity of paired peaks.

The most striking difference between non-coastal samples and the terrestrial and coastal marine samples in Table 7 is the much greater number of highly unsaturated compounds $(\mathrm{H} / \mathrm{C}<1)$ that are detected in the FTICR mass spectra of the terrestrial and coastal marine samples. An anonymous reviewer suggested that the ionization of less abundant acids is suppressed in samples containing high concentrations of fatty acids, so the very low numbers of unsaturated compounds in the mass spectra of non-coastal samples may be a consequence of the much greater levels of fatty acids in those samples (see Table 8). It is certainly the case that the mass spectra in which peak intensity is dominated by fatty acids are exactly the same mass spectra that have very few paired peaks with $\mathrm{H} / \mathrm{C}<1$.

FTICR mass spectra are given in Fig. 9 for the five RO/ ED samples and in Fig. 10 for the other four samples. Molecular formulae are also presented as van Krevelen plots of molar $\mathrm{H} / \mathrm{C}$ versus molar $\mathrm{O} / \mathrm{C}$ ratios in Figs. 9 and 10. The FTICR mass spectra of the four non-coastal RO/ED samples (S706-1, S706-8, S1006-3, and S1006-4) and the surface UDOM sample have a substantial percentage of peak intensity at $\mathrm{m} / \mathrm{z}$ values of 300 or less, with essentially no peaks above $m / z=800$. In contrast, the RO/ED sample from the mouth of the Ogeechee River (S1006-6), the deep UDOM sample, and the two samples from the Suwannee River have noticeably less peak intensity at $m / z<300$. The coastal RO/ED sample and the two samples from the Suwannee River contain molecules with $\mathrm{m} / \mathrm{z}$ values that reach $1000 \mathrm{Da}$ or higher.

Each van Krevelen plot in Figs. 9 and 10 contains a dashed line at $\mathrm{H} / \mathrm{C}=1$, which only serves as a reference in the discussion of these plots. The non-coastal RO/ED samples in Fig. 9 have very similar distributions of chemical composition, and compounds with $\mathrm{H} / \mathrm{C}<1$ are quite rare in the mass spectra of these samples. The mass spectra and van Krevelen plots of the surface and deep UDOM samples in Fig. 10 are similar to those of the non-coastal $\mathrm{RO} / \mathrm{ED}$ samples, with very few compounds having $\mathrm{H} /$ $\mathrm{C}<1$. In sharp contrast, compounds having $\mathrm{H} / \mathrm{C}<1$ are

Table 7

Overview of the FTICR mass spectra of the five RO/ED samples, surface UDOM, deep UDOM, Suwannee River NOM, and Suwannee River FA.

\begin{tabular}{|c|c|c|c|c|c|c|c|c|c|c|}
\hline \multirow[t]{2}{*}{ Sample } & \multicolumn{2}{|c|}{ Total peaks } & \multicolumn{2}{|c|}{ Assigned peaks } & \multicolumn{2}{|c|}{ Paired peaks } & \multicolumn{2}{|c|}{ Singly-charged peaks } & \multicolumn{2}{|c|}{ Peaks with $\mathrm{H} / \mathrm{C}<1$} \\
\hline & $\mathrm{S}: \mathrm{N} \geqslant 2^{\mathrm{a}}$ & $\mathrm{S}: \mathrm{N} \geqslant 3^{\mathrm{a}}$ & Count & Intensity $^{\mathrm{b}}$ & Count & Intensity $^{\mathrm{b}}$ & Count & Intensity $^{\mathrm{c}}$ & Count & Intensity $^{\mathrm{c}}$ \\
\hline S706-1 & 13,807 & 13,347 & 7085 & 49.8 & 2960 & 37.5 & 2862 & 99.4 & 26 & 0.38 \\
\hline S706-8 & 20,536 & 11,061 & 8147 & 48.5 & 2652 & 30.6 & 2554 & 99.4 & 10 & 0.11 \\
\hline S1006-3 & 8230 & 8230 & 4352 & 43.2 & 1806 & 30.5 & 1798 & 99.9 & 4 & 0.07 \\
\hline S1006-4 & 15,716 & 12,428 & 7541 & 51.1 & 3268 & 37.9 & 3130 & 99.3 & 16 & 0.06 \\
\hline S1006-6 & 29,808 & 25,328 & 14,952 & 67.7 & 7756 & 58.1 & 6148 & 95.5 & 1174 & 8.53 \\
\hline Surface UDOM & 10,839 & 10,839 & 6112 & 42.1 & 2982 & 31.4 & 2342 & 91.9 & 8 & 0.09 \\
\hline Deep UDOM & 20,846 & 11,542 & 9077 & 54.3 & 3982 & 42.2 & 2100 & 70.7 & 60 & 0.31 \\
\hline Suwannee NOM & 26,062 & 17,327 & 14,516 & 78.7 & 7398 & 66.9 & 6828 & 98.8 & 3700 & 39.5 \\
\hline Suwannee FA & 28,514 & 20,051 & 18,175 & 86.8 & 9744 & 75.9 & 7928 & 96.5 & 5820 & 45.4 \\
\hline
\end{tabular}

${ }^{a} \mathrm{~S}: \mathrm{N}$ is the signal-to-noise ratio.

${ }^{b}$ Percentage of the total intensity of peaks having $\mathrm{S}: \mathrm{N} \geqslant 2$.

${ }^{c}$ Percentage of the total intensity of paired peaks. 
Table 8

Fatty acid peaks in the FTICR mass spectra of the five RO/ED samples, surface UDOM, deep UDOM, Suwannee River NOM, and Suwannee River FA.

\begin{tabular}{|c|c|c|c|c|c|c|c|c|c|c|c|}
\hline \multirow[t]{2}{*}{ Sample } & \multicolumn{2}{|c|}{ Total fatty acids } & \multicolumn{2}{|c|}{$\begin{array}{l}\text { Saturated fatty } \\
\text { acids }\end{array}$} & \multicolumn{2}{|c|}{$\begin{array}{l}\text { Monounsaturated fatty } \\
\text { acids }\end{array}$} & \multicolumn{2}{|c|}{$\begin{array}{l}\text { Polyunsaturated fatty } \\
\text { acids }\end{array}$} & \multicolumn{3}{|c|}{$\begin{array}{l}\text { Even and odd carbon fatty } \\
\text { acids }\end{array}$} \\
\hline & Count & Intensity $^{\mathrm{a}}$ & Count & Intensity $^{\mathrm{a}}$ & Count & Intensity $^{\mathrm{a}}$ & Count & Intensity $^{\mathrm{a}}$ & Even & Odd & Ratio $^{\text {b }}$ \\
\hline S706-1 & 120 & 42.8 & 28 & 25.3 & 22 & 14.7 & 70 & 2.8 & 72 & 48 & 3.3 \\
\hline S706-8 & 90 & 23.8 & 34 & 14.7 & 18 & 7.6 & 38 & 1.5 & 54 & 36 & 3.1 \\
\hline S1006-3 & 98 & 57.8 & 34 & 35.2 & 24 & 19.6 & 40 & 3.1 & 56 & 42 & 3.6 \\
\hline S1006-4 & 104 & 22.9 & 28 & 13.6 & 18 & 7.8 & 58 & 1.5 & 58 & 46 & 3.0 \\
\hline S1006-6 & 122 & 5.6 & 30 & 3.7 & 16 & 1.4 & 76 & 0.5 & 72 & 50 & 3.5 \\
\hline Surface UDOM & 78 & 15.8 & 20 & 9.6 & 16 & 4.7 & 42 & 1.5 & 50 & 28 & 2.8 \\
\hline Deep UDOM & 44 & 7.3 & 20 & 5.2 & 12 & 1.8 & 12 & 0.3 & 26 & 18 & 3.6 \\
\hline Suwannee NOM & 84 & 1.9 & 14 & 0.8 & 12 & 0.6 & 58 & 0.5 & 48 & 36 & 2.7 \\
\hline Suwannee FA & 70 & 0.5 & 14 & 0.2 & 10 & 0.2 & 46 & 0.2 & 36 & 34 & 2.2 \\
\hline
\end{tabular}

${ }^{a}$ Percentage of the total intensity of paired peaks (see Table 7).

${ }^{\mathrm{b}}$ Even:Odd ratio of peak intensities of fatty acids.
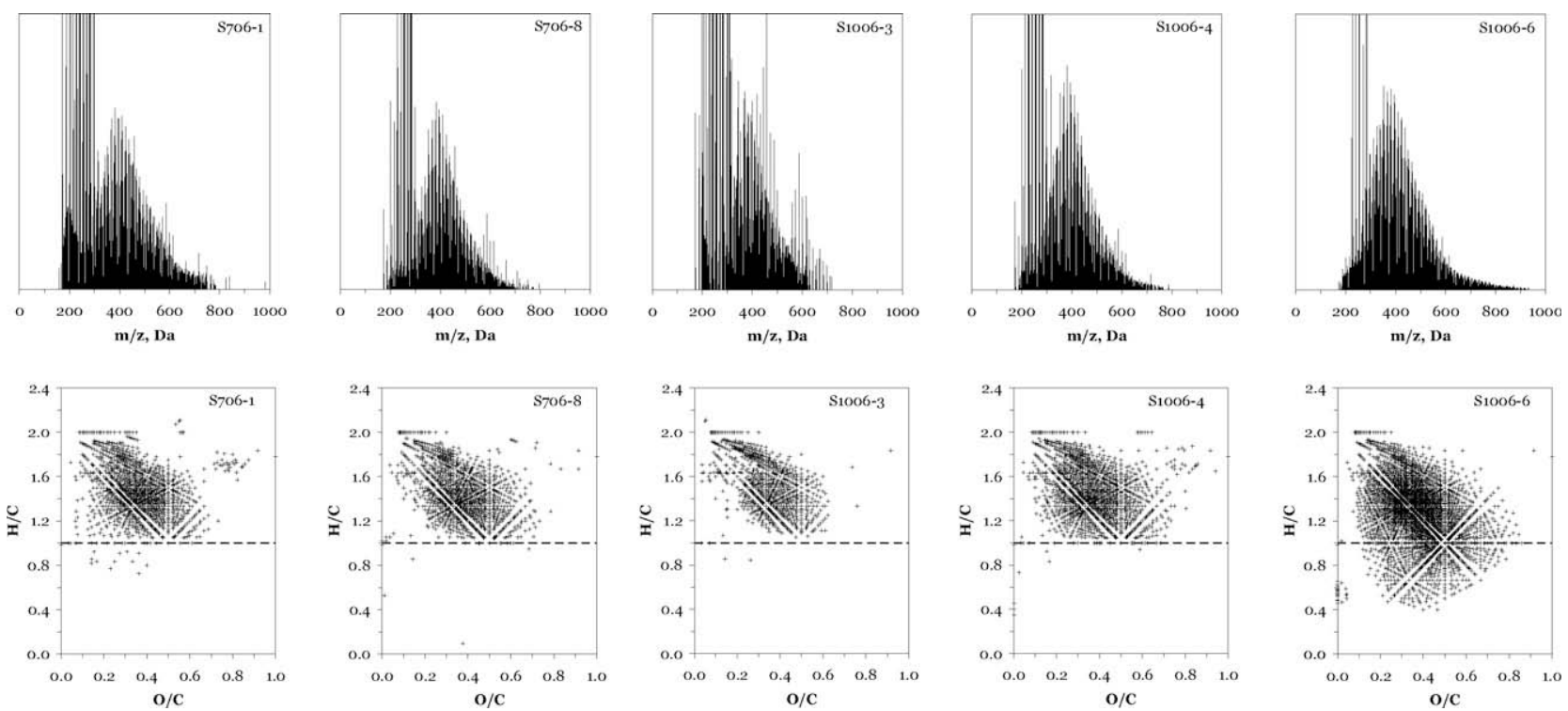

Fig. 9. FTICR mass spectra and van Krevelen plots for the five RO/ED samples of marine DOM. S1006-6 is the coastal sample.

abundant in the mass spectra of the two terrestrially derived samples from the Suwannee River, and such compounds account for $15 \%$ of peaks and $9 \%$ of peak intensity in the mass spectrum of the coastal RO/ED sample, which is intermediate between non-coastal and terrestrial samples. The much higher proportion of unsaturated molecules in the coastal $\mathrm{RO} / \mathrm{ED}$ sample, relative to the non-coastal samples, is consistent with $\mathrm{UV}$, elemental $(\mathrm{C} / \mathrm{N}),{ }^{1} \mathrm{H} \mathrm{NMR}$, and ${ }^{13} \mathrm{C}$ NMR data that also indicate a strong terrestrial influence on the coastal sample.

There is a strong similarity between the van Krevelen plots for the surface and deep UDOM samples in Fig. 10 and those of the non-coastal RO/ED samples in Fig. 9. The loci of points in the van Krevelen plots of non-coastal $\mathrm{RO} / \mathrm{ED}$ samples are somewhat more widely dispersed across the compositional space than is the case for the surface and deep UDOM samples. This outcome is consistent with ${ }^{13} \mathrm{C}$ NMR data, which show that the RO/ED samples contain components of both the UF and XAD samples, and with the much greater overall yield of marine DOM in the RO/ED process $(75 \pm 12 \%)$ than by UF $(30 \pm 11 \%)$.

It is really striking that so few unsaturated peaks are found in the mass spectra of both the RO/ED and UF samples of non-coastal marine DOM, especially considering that these samples, the coastal RO/ED sample, and the two samples from the Suwannee River were all processed identically. As noted by an anonymous reviewer, the near absence of unsaturated compounds in the mass spectra of non-coastal samples could be a matrix effect arising from high levels of fatty acids in those samples (see earlier discussion and subsequent discussion of Table 8); however, the proton NMR spectra of non-coastal RO/ED samples (see Table 6) and surface and deep UDOM samples from Station ALOHA (Hertkorn et al., 2006) provide independent evidence that those samples contain very little peak intensity that can be attributed to either olefinic or aromatic moieties. In contrast to the results of this study, Koch et al. (2005) generated van Krevelen plots from FTICR 

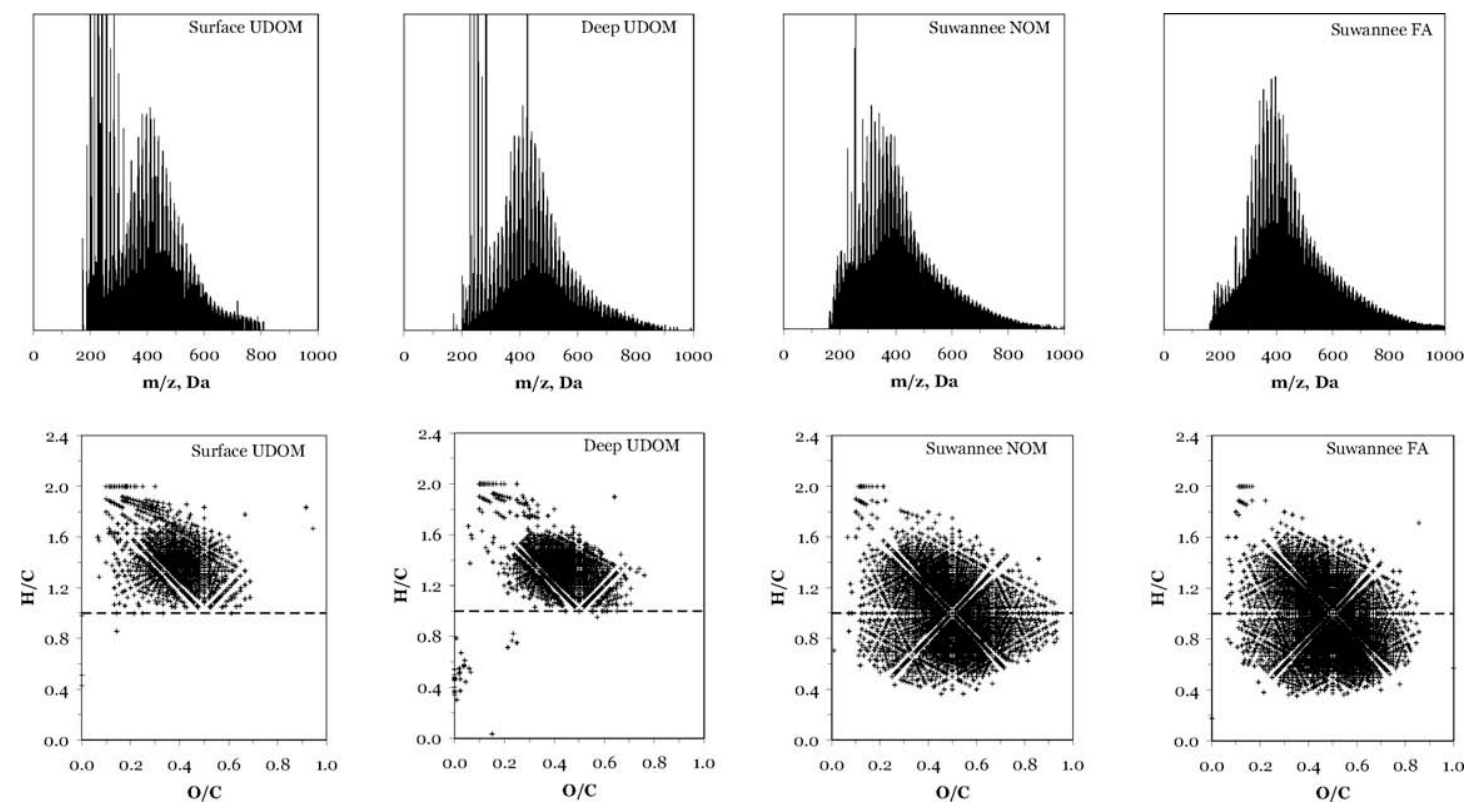

Fig. 10. FTICR mass spectra and van Krevelen plots for surface UDOM, deep UDOM, Suwannee River NOM, and Suwannee River FA.

mass spectra of samples of marine DOM from a Brazilian mangrove swamp, where terrestrial inputs of DOM are a certainty, and from several depths in the Weddell Sea. They observed very many peaks whose molecular formulae had $\mathrm{H} / \mathrm{C}$ ratios of less than one. Their DOM samples were isolated from seawater using the $\mathrm{C}_{18}$ method, which is known to preferentially extract aromatic compounds (see Louchouarn et al., 2000; Simjouw et al., 2005), so the relatively greater occurrence of unsaturated molecular formulae in their mass spectra may simply be another consequence of the preferential extraction of such compounds by $\mathrm{C}_{18}$ adsorbents.

A detailed evaluation of the subset of peaks having the molecular formulae of fatty acids is given in Table 8 . All mass spectra were screened for paired peaks having $m / z<400 \mathrm{Da}$ and molecular formulae that correspond to saturated $\left(\mathrm{C}_{n} \mathrm{H}_{2 n} \mathrm{O}_{2}\right)$, mono-unsaturated $\left(\mathrm{C}_{n} \mathrm{H}_{2 n-2} \mathrm{O}_{2}\right)$, and poly-unsaturated $\left(\mathrm{C}_{n} \mathrm{H}_{2 n-4} \mathrm{O}_{2}-\mathrm{C}_{n} \mathrm{H}_{2 n-12} \mathrm{O}_{2}\right)$ fatty acids. Compounds containing up to $26 \mathrm{C}$ atoms are included in this analysis, if they are present in the samples. Admittedly, exact masses and molecular formulae are insufficient proof of structure, because many possible isomeric compounds share these characteristics. Sleighter et al. (2008) have shown recently that some peaks in the FTICR mass spectrum of dissolved organic matter have the exact masses of fatty acids, and they have assumed that these peaks are attributable to fatty acids. Certainly, seawater is known to contain fatty acids (McCallister et al., 2006), and fatty acids are much more readily ionized using FTICR-MS in negative ion mode than non-acidic compounds having the same molecular formulae, so it is reasonable to assume that these peaks actually are fatty acids. The potential contributions of fatty acids to the number of peaks and to the peak intensity of each FTICR mass spectrum are tabulated in Table 8 . Fatty acids account for an average of $37 \%$ of the peak intensity in mass spectra of the four non-coastal
$\mathrm{RO} / \mathrm{ED}$ samples and $12 \%$ of peak intensity in mass spectra of the surface and deep UDOM samples. In contrast, fatty acids account for only $1.2 \%$ of peak intensity in the mass spectra of samples from the Suwannee River and $5.6 \%$ of peak intensity in the coastal RO/ED sample.

Even though FTICR mass spectra are known to be nonquantitative, the relatively greater abundance of fatty acids in the RO/ED samples than in the UDOM samples is fully consistent with the ${ }^{13} \mathrm{C}$ NMR results that were discussed earlier, for which $\mathrm{RO} / \mathrm{ED}$ samples had consistently greater peak intensity in the chemical shift range of alkyl $\mathrm{C}$. The effect of fatty acids on ${ }^{13} \mathrm{C}$ NMR spectra should be much more evident for alkyl $\mathrm{C}$ than for carboxyl $\mathrm{C}$, simply because the fatty acids themselves contain far more alkyl $\mathrm{C}$ than carboxyl C. As noted earlier, the average ${ }^{1} \mathrm{H}$ NMR spectrum of RO/ED samples contains more peak intensity at a chemical shift of around $1.2 \mathrm{ppm}$ than can be explained by a mixture of the average spectra of UF and SPE samples, which is consistent with a relatively greater percentage of fatty acids in the samples that are isolated using the coupled RO/ED process.

Within the group of fatty acids, the peak counts and intensities of saturated fatty acids (SFA), mono-unsaturated fatty acids (MUFA), and poly-unsaturated fatty acids (PUFA) vary from sample to sample (see Table 8). On the basis of peak intensity, the relative proportions of the three classes of fatty acids are consistently in the order of SFA > MUFA $>>$ PUFA for the five RO/ED samples. The RO/ ED samples have an average SFA:MUFA:PUFA ratio of approximately 10:5:1 and an average Even/Odd ratio of 3.3. Similarly, the surface and deep UDOM samples have an average SFA:MUFA:PUFA ratio of approximately 11:4:1 and an average Even/Odd ratio of 3.2. In contrast, the Suwannee River samples have an average SFA:MUFA:PUFA of approximately 1.3:1.1:1 and an average Even/Odd ratio of 2.5. The generally greater degree of 
unsaturation of compounds that are detected in the FTICR mass spectra of terrestrially derived DOM from the Suwannee River is also observed within this single class of organic acids - the fatty acids.

McCallister et al. (2006) measured fatty acids on six samples of DOM that were isolated from the York River estuary (Virginia, USA) using UF with a $3 \mathrm{kDa}$ membrane. Fatty acids were liberated by saponification in $\mathrm{KOH}$ and quantified by gas chromatographic analysis of their methyl esters, so their analysis yields the sum of free and bound fatty acids. Their samples which were collected in October, 2000 are compared here with the RO/ED samples, which were collected in July, 2006 and October, 2006. Their data were converted into molar units and then aggregated to obtain estimates of SFA, MUFA, PUFA, and the Even/Odd ratio. The average SFA:MUFA:PUFA ratio for their six samples is approximately 30:9:1, and the average Even/ Odd ratio is 4.1. The results obtained from FTICR-MS spectra of the five RO/ED samples of marine DOM are considered to be in reasonable agreement with results that were obtained directly by gas chromatographic analysis of hydrolyzed samples of estuarine DOM, especially considering that only free fatty acids are detected by FTICR mass spectrometry and total hydrolysable fatty acids were measured by McCallister et al. (2006).

\section{CONCLUSIONS}

The RO/ED process offers a robust solution to the problem of isolating marine DOM. At its present stage of development, the RO/ED process can be used to remove more than $95 \%$ of the water and more than $99.995 \%$ of the sea salts from a $200 \mathrm{~L}$ sample of seawater in $6-8 \mathrm{~h}$ of processing at sea, while recovering an average of $75 \%$ of DOC in the sample. This yield of DOC is roughly a factor of three better than is typically obtained by any other single method (UF, $\mathrm{C}_{18}, \mathrm{XAD}$ ) in non-coastal seawater. Samples that have been isolated using this method still contain residual sea salts; however, excellent results can be obtained when advanced analytical methods such as ${ }^{13} \mathrm{C}$ and ${ }^{1} \mathrm{H}$ NMR spectrometry and FTICR mass spectrometry are used for their characterization.

Both UV absorbance measurements and molar $\mathrm{C} / \mathrm{N}$ ratios of the RO/ED samples of marine DOM confirm that, at least with respect to these properties, the isolated $\mathrm{RO} /$ ED samples are unbiased relative to source waters from which the samples were isolated.

The ${ }^{13} \mathrm{C}$ NMR spectra of the RO/ED samples of marine DOM are consistent with the nature of the samples, e.g., the strongest aromatic $\mathrm{C}$ peak is found in the coastal sample, and samples isolated from comparable marine environments have very similar spectra. The RO/ED samples contain most of the components of marine DOM that have been isolated separately using either UF or XAD resins. The RO/ED samples contain relatively more alkyl $\mathrm{C}$ and relatively less alkoxy carbon than UF samples, and ${ }^{13} \mathrm{C}$ NMR difference spectra suggest that a significant fraction of the "new" DOM that is recovered by RO/ED process closely resembles carboxyl-rich alicyclic molecules (CRAM), which were postulated by Hertkorn et al.
(2006) to be a major constituent of marine DOM. The ${ }^{1} \mathrm{H}$ NMR spectra of the RO/ED samples of marine DOM generally support the conclusions that have been made based on the ${ }^{13} \mathrm{C}$ NMR spectra. These spectra demonstrate further that the S706-1 sample is comparable to the other four samples and that the RO/ED samples may contain a greater percentage of fatty acids than samples that have been isolated using UF or SPE methods.

FTICR-MS data are not quantitative, but compounds having the molecular formulae of fatty acids accounted for $37 \%$ of peak intensity in the mass spectra of RO/ED samples of non-coastal marine DOM. Somewhat lower levels of fatty acids $(12 \%)$ were found in samples of marine DOM that were isolated using UF. Terrestrially derived samples of DOM from the Suwannee River had the lowest levels of fatty acids ( $1 \%$ of peak intensity), and the coastal $\mathrm{RO} / \mathrm{ED}$ sample had an intermediate level of fatty acids $(6 \%$ of peak intensity).

Van Krevelen plots revealed that $42 \%$ of the peak intensity in the FTICR mass spectra of terrestrially derived DOM from the Suwannee River is attributable to highly unsaturated compounds having molar $\mathrm{H} / \mathrm{C}<1$. Less than $0.2 \%$ of peak intensity in the mass spectra of non-coastal samples of marine DOM, whether isolated using UF or the RO/ED process, is attributable to compounds having molar $\mathrm{H} / \mathrm{C}<1$. The coastal $\mathrm{RO} / \mathrm{ED}$ sample was intermediate between these extremes, with $9 \%$ of peak intensity being attributable to compounds having molar $\mathrm{H} / \mathrm{C}<1$.

All results $\left(\mathrm{C} / \mathrm{N}, \mathrm{UV},{ }^{13} \mathrm{C} \quad \mathrm{NMR},{ }^{1} \mathrm{H}\right.$ NMR, and FTICR-MS) reveal clear differences between non-coastal and coastal marine DOM, and the observed differences confirm, not surprisingly, that the coastal sample contains a significant amount of terrestrially derived DOM. It is thus reasonable to conclude that the coupled RO/ED process enables the isolation (at sea) of significant quantities of chemically representative DOM in high yield from both coastal and non-coastal surface seawater.

\section{ACKNOWLEDGMENTS}

This material is based upon work supported by the National Science Foundation (NSF) under Grants No. 0425624 and 0425603. Any opinions, findings, and conclusions or recommendations expressed in this material are those of the authors and do not necessarily reflect the views of NSF. The authors express their sincere appreciation to Dr. Mary Rezac, who initiated the contact between scientists and engineers that made this work possible. The authors also thank Dr. Poulomi Sannigrahi and Ms. Cindy Jackson for help at sea and in the laboratory and especially thank Captain Raymond Sweatte and the excellent crew of the R/V Savannah for two great and productive cruises.

\section{REFERENCES}

Aluwihare L. I., Repeta D. J. and Chen R. F. (1997) A major biopolymeric component to dissolved organic carbon in surface sea water. Nature 387, 166-169.

Amador J. A., Milne P. J., Moore C. A. and Zika R. G. (1990) Extraction of chromophoric substances from seawater. Mar. Chem. 29, 1-17. 
Benner R. and Opsahl S. (2001) Molecular indicators of the sources and transformations of dissolved organic matter in the Mississippi River plume. Org. Geochem. 32, 597-611.

Benner R. and Strom M. (1993) A critical evaluation of the analytical blank associated with DOC measurements by hightemperature catalytic oxidation. Mar. Chem. 41, 153-160.

Benner R., Pakulski J. D., McCarthy M., Hedges J. I. and Hatcher P. G. (1992) Bulk chemical characterization of dissolved organic matter in the ocean. Science 255, 1561-1564.

Benner R., Biddanda B., Black B. and McCarthy M. (1997) Abundance, size distribution, and stable carbon and nitrogen isotopic compositions of marine organic matter isolated by tangential-flow ultrafiltration. Mar. Chem. 57, 243-263.

Benner R., Louchouarn P. and Amon, R. M. W. (2005) Terrigenous dissolved organic matter in the Arctic Ocean and its transport to surface and deep waters of the North Atlantic. Global Biogeochem. Cycles, 19, GB2025, doi: 10.1029/ 2004GB002398.

Blough, N. V. and Green, S. A. (1995) Spectroscopic characterization and remote sensing of nonliving organic matter. In The Role of Nonliving Organic Matter in the Earth's Carbon Cycle (eds. R. G. Zepp, and Ch. Sonntag). Dahlem Workshop Reports, Environmental Sciences Research Report 16, John Wiley \& Sons, Chichester, UK, pp. 23-45.

Bronk D. A. (2002) Dynamics of DON. In Biogeochemistry of Marine Dissolved Organic Matter (eds. D. A. Hansell and C. A. Carlson). Academic Press, pp. 153-247.

Clair T. A., Kramer J. R., Sydor M. and Eaton D. (1991) Concentration of aquatic dissolved organic matter by reverse osmosis. Water Res. 25, 1033-1037.

Cook R. L., Langford C. H., Yamdagni R. and Preston C. M. (1996) A modified cross-polarization magic angle spinning ${ }^{13} \mathrm{C}$ NMR procedure for the study of humic materials. Anal. Chem. 68, 3979-3986.

Diaz J., Ingall E., Benitez-Nelson C., Paterson D., de Jonge M. D., McNulty I. and Brandes J. A. (2008) Marine polyphosphate: a key player in geologic phosphorus sequestration. Science 320, 652-655.

Dittmar T., Koch B., Hertkorn N. and Kattner G. (2008) A simple and efficient method for the solid-phase extraction of dissolved organic matter (SPE-DOM) from seawater. Limnol. Oceanogr. Methods 6, 230-235.

Druffel E. R. M., Williams P. M., Bauer J. E. and Ertel J. R. (1992) Cycling of dissolved and particulate organic matter in the open ocean, J. Geophys. Res. Oceans 97, 15639-15659.

$\mathrm{Fu} \mathrm{T}$. and Pocklington R. (1983) Quantitative adsorption of organic matter from seawater on solid matrices. Mar. Chem. 13, 255-264.

Guo L. and Santschi P. H. (1997) Isotopic and elemental characterization of colloidal organic matter from the Chesapeake Bay and Galveston Bay. Mar. Chem. 59, 1-15.

Guo L., Santschi P. H. and Warnken K. W. (1995) Dynamics of dissolved organic carbon (DOC) in oceanic environments. Limnol. Oceanogr. 40, 1392-1403.

Guo L., Santschi P. H., Cifuentes L. A., Trumbore S. E. and Southon J. (1996) Cycling of high-molecular-weight dissolved organic matter in the Middle Atlantic Bight as revealed by carbon isotopic $\left({ }^{13} \mathrm{C}\right.$ and $\left.{ }^{14} \mathrm{C}\right)$ signatures. Limnol. Oceanogr. 41, $1242-1252$.

Guo L., Tanaka N., Schell D. M. and Santschi P. H. (2003) Nitrogen and carbon isotopic composition of high-molecularweight dissolved organic matter in marine environments. Mar. Ecol. Prog. Ser. 252, 51-60.

Gurtler B. K., Vetter T. A., Perdue E. M., Ingall E., Koprivnjak J.F. and Pfromm P. H. (2008) Combining reverse osmosis and pulsed electrical current electrodialysis for improved recovery of dissolved organic matter from seawater. J. Mem. Sci. 323, 328-336.

Harvey G. R., Boran D. A., Chesal L. A. and Tokar J. M. (1983) The structure of marine fulvic and humic acids. Mar. Chem. 12, 119-132.

Hedges J. I. and Stern J. H. (1984) Carbon and nitrogen determinations of carbonate-containing solids. Limnol. Oceanogr. 29, 657-663.

Hedges J. I., Hatcher P. G., Ertel J. R. and Meyers-Schulte K. J. (1992) A comparison of dissolved humic substances from seawater with Amazon River counterparts by ${ }^{13} \mathrm{C}$ NMR spectrometry. Geochim. Cosmochim. Acta 56, 1753-1757.

Hedges J. I., Keil R. G. and Benner R. (1997) What happens to terrestrial organic matter in the ocean? Org. Geochem. 27, 195212.

Hernes P. J. and Benner R. (2002) Transport and diagenesis of dissolved and particulate terrigenous organic matter in the North Pacific Ocean. Deep-Sea Res. I 49, 2119-2132.

Hertkorn N., Benner R., Frommberger M., Schmitt-Kopplin P., Witt M., Kaiser K., Kettrup A. and Hedges J. I. (2006) Characterization of a major refractory component of marine dissolved organic matter. Geochim. Cosmochim. Acta 70, 29903010.

Kim D. H., Moon S.-H. and Cho J. (2002) Investigation of the adsorption and transport of natural organic matter (NOM) in ion exchange membranes. Desalination 151, 11-20.

Kitidis V., Stubbins A. P., Uher G., Goddard R. C. U., Law C. S. and Woodward E. M. S. (2006) Variability of chromophoric organic matter in surface waters of the Atlantic Ocean. DeepSea Res. II 53, 1666-1684.

Kitis M., Kilduff J. E. and Karanfil T. (2001) Isolation of dissolved organic matter (DOM) from surface waters using reverse osmosis and its impact on the reactivity of DOM to formation and speciation of disinfection by-products. Water Res. 35, 2225-2234.

Koch B. P., Witt M., Engbrodt R., Dittmar T. and Kattner G. (2005) Molecular formulae of marine and terrigenous dissolved organic matter detected by electrospray ionization Fourier transform ion cyclotron resonance mass spectrometry. Geochim. Cosmochim. Acta 69, 3299-3308.

Koprivnjak J.-F., Perdue E. M. and Pfromm P. H. (2006) Coupling reverse osmosis with electrodialysis to isolate natural organic matter from fresh waters. Water Res. 40, 3385-3392.

Lee S. and Elimelech M. (2007) Salt cleaning of organic-fouled reverse osmosis membranes. Water Res. 41, 1134-1142.

Louchouarn P., Opsahl S. and Benner R. (2000) Isolation and quantification of dissolved lignin from natural waters using solid-phase extraction and GC/MS. Anal. Chem. 72, 2780-2787.

Malcolm R. L. (1990) The uniqueness of humic substances in each of soil, stream, and marine environments. Anal. Chim. Acta 232, 19-30.

McCallister S. L., Bauer J. E., Ducklow H. W. and Canuel E. A. (2006) Sources of estuarine dissolved and particulate organic matter: a multi-tracer approach. Org. Geochem. 37, 454-468.

Meyers-Schulte K. J. and Hedges J. I. (1986) Molecular evidence for a terrestrial component of organic matter dissolved in ocean water. Nature 321, 61-63.

Mills G. L. and Quinn J. G. (1981) Isolation of dissolved organic matter and dissolved copper-organic complexes from estuarine waters using reverse-phase liquid chromatography. Mar. Chem. 10, 93-102.

Mopper K., Stubbins A., Ritchie J. D., Bialk H. M. and Hatcher P. G. (2007) Advanced instrumental approaches for characterization of marine dissolved organic matter: extraction techniques, mass spectrometry, and nuclear magnetic resonance spectroscopy. Chem. Rev. 107, 419-442. 
Obernosterer I. and Herndl G. J. (2000) Differences in the optical and biological reactivity of the humic and nonhumic dissolved organic carbon component in two contrasting coastal marine environments. Limnol. Oceanogr. 45, 1120-1129.

Onori G. (1988) Ionic hydration in sodium chloride solutions. $J$. Chem. Phys. 89, 510-516.

Peersen O. B., Wu X., Kustanovich I. and Smith S. O. (1993) Variable-amplitude cross-polarization MAS NMR. J. Mag. Res. 104, 334-339.

Perdue, E. M. and Benner, R. (in press) Marine organic matter. In Biophysico-chemical Processes Involving Natural Nonliving Organic Matter in Environmental Systems (eds. N. Senesi, B. Xing and P. M. Huang). IUPAC, in press.

Perdue E. M. and Ritchie J. D. (2003) Dissolved organic matter in fresh waters. In Surface and Ground Water, Weathering, Erosion and Soils, vol. 5 (ed. J. I. Drever) (eds. H. D. Holland and K. K. Turekian). Elsevier-Pergamon, Oxford, Holland, pp. 273-318.

Sannigrahi P., Ingall E. D. and Benner R. (2005) Cycling of dissolved and particulate organic matter at station Aloha: Insights from ${ }^{13} \mathrm{C}$ NMR spectroscopy coupled with elemental, isotopic and molecular analyses. Deep-Sea Res. I 52, 14291444.

Schaefer J. and Stejskal E. O. (1976) Carbon-13 nuclear magnetic resonance of polymers spinning at magic angle. J. Am. Chem. Soc. 98, 1031-1032.

Serkiz S. M. and Perdue E. M. (1990) Isolation of dissolved organic matter from the Suwannee River using reverse osmosis. Water Res. 24(7), 911-916.
Simjouw J.-P., Minor E. C. and Mopper K. (2005) Isolation and characterization of estuarine dissolved organic matter: comparison of ultrafiltration and $\mathrm{C}_{18}$ solid-phase extraction techniques. Mar. Chem. 96, 219-235.

Sleighter R. L., McKee G. A., Liu Z. and Hatcher P. G. (2008) Naturally present fatty acids as internal calibrants for Fourier transform mass spectra of dissolved organic matter. Limnol. Oceanogr. Methods 6, 246-253.

Stuermer D. H. and Harvey G. R. (1974) Humic substances from seawater. Nature 250, 480-481.

Stuermer D. H. and Harvey G. R. (1977) The isolation of humic substances and alcohol-soluble organic matter from seawater. Deep-Sea Res. 24, 303-309.

Sun L., Perdue E. M. and McCarthy J. F. (1995) Using reverse osmosis to obtain organic matter from surface and ground waters. Water Res. 29, 1471-1477.

Vetter T. A., Perdue E. M., Ingall E., Koprivnjak J.-F. and Pfromm P. H. (2007) Combining reverse osmosis and electrodialysis for more complete recovery of dissolved organic matter from seawater. Sep. Purif. Technol. 56, 383-387.

Wilson M. A., Gillam A. H. and Collin P. J. (1983) Analysis of the structure of dissolved marine humic substances and their phytoplanktonic precursors by ${ }^{1} \mathrm{H}$ and ${ }^{13} \mathrm{C}$ nuclear magnetic resonance. Chem. Geol. 40, 187-201.

Associate editor: Thomas S. Bianchi 